\title{
Efficient Design and Analysis of Lightweight Reinforced Core Sandwich and PRSEUS Structures
}

Brett A. Bednarcyk

Glenn Research Center, Cleveland, Ohio

Phillip W. Yarrington, Ryan C. Lucking, Craig S. Collier, and James J. Ainsworth

Collier Research Corporation, Newport News, Virginia

Elias A. Toubia

University of Dayton, Dayton, Ohio

An Erratum was added to this report November 2013. 


\section{NASA STI Program . . . in Profile}

Since its founding, NASA has been dedicated to the advancement of aeronautics and space science. The NASA Scientific and Technical Information (STI) program plays a key part in helping NASA maintain this important role.

The NASA STI Program operates under the auspices of the Agency Chief Information Officer. It collects, organizes, provides for archiving, and disseminates NASA's STI. The NASA STI program provides access to the NASA Aeronautics and Space Database and its public interface, the NASA Technical Reports Server, thus providing one of the largest collections of aeronautical and space science STI in the world. Results are published in both non-NASA channels and by NASA in the NASA STI Report Series, which includes the following report types:

- TECHNICAL PUBLICATION. Reports of completed research or a major significant phase of research that present the results of NASA programs and include extensive data or theoretical analysis. Includes compilations of significant scientific and technical data and information deemed to be of continuing reference value. NASA counterpart of peer-reviewed formal professional papers but has less stringent limitations on manuscript length and extent of graphic presentations.

- TECHNICAL MEMORANDUM. Scientific and technical findings that are preliminary or of specialized interest, e.g., quick release reports, working papers, and bibliographies that contain minimal annotation. Does not contain extensive analysis.

- CONTRACTOR REPORT. Scientific and technical findings by NASA-sponsored contractors and grantees.
- CONFERENCE PUBLICATION. Collected papers from scientific and technical conferences, symposia, seminars, or other meetings sponsored or cosponsored by NASA.

- SPECIAL PUBLICATION. Scientific, technical, or historical information from NASA programs, projects, and missions, often concerned with subjects having substantial public interest.

- TECHNICAL TRANSLATION. Englishlanguage translations of foreign scientific and technical material pertinent to NASA's mission.

Specialized services also include creating custom thesauri, building customized databases, organizing and publishing research results.

For more information about the NASA STI program, see the following:

- Access the NASA STI program home page at http://www.sti.nasa.gov

- E-mail your question to help@sti.nasa.gov

- Fax your question to the NASA STI Information Desk at 443-757-5803

- Phone the NASA STI Information Desk at 443-757-5802

- Write to: STI Information Desk NASA Center for AeroSpace Information 7115 Standard Drive Hanover, MD 21076-1320 


\section{Efficient Design and Analysis of Lightweight Reinforced Core Sandwich and PRSEUS Structures}

Brett A. Bednarcyk

Glenn Research Center, Cleveland, Ohio

Phillip W. Yarrington, Ryan C. Lucking, Craig S. Collier, and James J. Ainsworth

Collier Research Corporation, Newport News, Virginia

Elias A. Toubia

University of Dayton, Dayton, Ohio

An Erratum was added to this report November 2013.

National Aeronautics and

Space Administration

Glenn Research Center

Cleveland, Ohio 44135 


\section{Acknowledgments}

The authors would like to acknowledge the technical contributions of Elias Toubia of WebCore Technologies, Alex Velicky, Victor $\mathrm{Li}$ and Nicolette Yovanof of the Boeing Company, and Dawn Jegley at NASA Langley Research Center. Development of the Reinforced Core Sandwich concept was funded by NASA under the Advanced Composite Technology (ACT) Program, COTR Steven Arnold, NASA Glenn Research Center. Development of the PRSEUS contract was funded by The Boeing Company, Huntington Beach, California.

\section{Erratum}

Issued November 2013 for

NASA/TM-2011-217198

Efficient Design and Analysis of Lightweight Reinforced Core Sandwich and PRSEUS Structures Brett A. Bednarcyk, Phillip W. Yarrington, Ryan C. Lucking, Craig S. Collier, and James J. Ainsworth

December 2011

The following author's name and affiliation has been added to the report:

Elias A. Toubia

University of Dayton

Dayton, Ohio

The Acknowlegments section has been changed to read as follows:

The authors would like to acknowledge the technical contributions of Alex Velicky, Victor Li and Nicolette Yovanof of the Boeing Company, and Dawn Jegley at NASA Langley Research Center. Development of the Reinforced Core Sandwich concept was funded by NASA under the Advanced Composite Technology (ACT) Program, COTR Steven Arnold, NASA Glenn Research Center. Development of the PRSEUS contract was funded by The Boeing Company, Huntington Beach, California.

Trade names and trademarks are used in this report for identification only. Their usage does not constitute an official endorsement, either expressed or implied, by the National Aeronautics and Space Administration.

Level of Review: This material has been technically reviewed by technical management.

Available from

NASA Center for Aerospace Information 7115 Standard Drive Hanover, MD 21076-1320
National Technical Information Service 5301 Shawnee Road Alexandria, VA 22312 


\title{
Efficient Design and Analysis of Lightweight Reinforced Core Sandwich and PRSEUS Structures
}

\author{
Brett A. Bednarcyk \\ National Aeronautics and Space Administration \\ Glenn Research Center \\ Cleveland, Ohio 44135 \\ Phillip W. Yarrington, Ryan C. Lucking, Craig S. Collier, and James J. Ainsworth \\ Collier Research Corporation \\ Newport News, Virginia 23606
}

\begin{abstract}
Design, analysis, and sizing methods for two novel structural panel concepts have been developed and incorporated into the HyperSizer Structural Sizing Software. Reinforced Core Sandwich (RCS) panels consist of a foam core with reinforcing composite webs connecting composite facesheets. Boeing's Pultruded Rod Stitched Efficient Unitized Structure (PRSEUS) panels use a pultruded unidirectional composite rod to provide axial stiffness along with integrated transverse frames and stitching. Both of these structural concepts are oven-cured and have shown great promise for applications in lightweight structures, but have suffered from the lack of efficient sizing capabilities similar to those that exist for honeycomb sandwich, foam sandwich, hat stiffened, and other, more traditional concepts. Now, with accurate design methods for RCS and PRSEUS panels available in HyperSizer, these concepts can be traded and used in designs as is done with the more traditional structural concepts. The methods developed to enable sizing of RCS and PRSEUS are outlined, as are results showing the validity and utility of the methods. Applications include several large NASA heavy lift launch vehicle structures.
\end{abstract}

\subsection{Introduction}

The HyperSizer Structural Sizing Software (Ref. 1) is used extensively in industry and government (particularly NASA) to design lightweight composite structures. The software couples with a shell and beam-based finite element (FE) model of a structure to obtain the global loads associated with each load case. These loads are then statistically processed by HyperSizer to arrive at design-to loads for each individual panel (or beam) that comprise the structure. These individual user-specified regions, each with its own design-to load, are referred to as components. Users specify the type (or types) of panels or beams to be considered for each component, along with ranges of geometric variables (e.g., facesheet thickness, web height, etc.) and material options (e.g., ply materials and layups). The software then selects the lightest weight design permutation from all of the possible specified candidates that provides all positive margins for all load cases and all failure modes. Each panel and beam component has thus been sized and potentially changed, so the software writes new panel and beam definitions to the FE model. The FE model is then re-analyzed to allow the global loads to redistribute in response to the new design produced by HyperSizer. The new loads are then taken by HyperSizer to produce a new, updated design, and the process continues iteratively until convergence is achieved.

Key to the sizing process described above is the ability of HyperSizer to localize further the design-to loads for the panels and beams to the object and ply level, where many of the failure modes are operative. For example, for a hat-stiffened panel, the panel level loads are first localized to the hat crown, web, and flange (as well as the facesheet open and closed span), which are referred to as objects. These object loads are then used to evaluate a particular design permutation versus local buckling failures. Further localization, to the level of the ply, enables evaluation of the design with respect to ply level failure criteria such as max stress, Tsai-Wu, and LaRC03. Only when a particular panel or beam design satisfies all failure modes (i.e., a positive margin of safety is calculated for all load cases) on all scales (including 
buckling at the panel level) is the design considered viable. Clearly, to calculate the margin of safety associated with each failure mode, accurate and efficient methods are needed not only localize the design to loads properly, but also to determine the failure load for a particular mode of failure. Such methods have now been developed and incorporated into HyperSizer for two new panel structural concepts; Reinforced Core Sandwich (RCS) (Refs. 2 and 3) and Boeing's Pultruded Rod Stitched Efficient Unitized Structure (PRSEUS) (Ref. 4).

\subsection{Reinforce Core Sandwich (RCS) Panels}

RCS is a novel sandwich panel concept produced by WebCore Technologies(Refs. 2 and 3) that combines features of foam core sandwich panels and stiffened panels. Note that this structural concept in the past has been referred to as WebCore (Ref. 5) and Fiber Reinforced Foam (FRF) (Refs. 6 and 7), but the name Reinforced Core Sandwich has been adopted by HyperSizer. This type of panel is constructed by starting with long strips of closed-cell structural foam, such as Rohacell (Evonik Industries), with rectangular cross sections. These strips are wrapped with dry carbon fibers and placed adjacent to each other on a tool with dry carbon fiber facesheet preforms on the top and bottom. The panel is then infiltrated with resin via vacuum-assisted resin transfer molding (VARTM) (Ref. 8). Once the panel is infiltrated and cured, the fiber overwraps located between the foam strips form integral composite webs (Figure 1). The webs provide significantly improved through-thickness shear strength compared to foam sandwich panels, while the foam provides support for the webs against local buckling. The webs also provide some axial strength and stiffness; however, this is not their primary purpose as they typically do not contain axial fibers, as the wrapping procedure requires a minimum helical angle of approximately $5^{\circ}$. The facesheets provide most of the panel's bending stiffness as they are located farther from the panel neutral axis. Biaxial RCS panels, with webs running in both directions can also be produced by cutting sticks from the dry core preform. However, in this case, only the webs running in one direction will be continuous.

Compared to aluminum honeycomb sandwich panels, RCS sandwich panels have the advantage of not requiring an adhesive between the facesheet and core, which adds parasitic mass, and debonding between facesheet and core is not typically an issue with RCS. Furthermore, RCS sandwich panels provide improved through-thickness shear strength in the web direction compared to aluminum honeycomb sandwich panels and they do not exhibit reduced shear strength as the panel thickness increases. Finally, the RCS sandwich concept is highly damage tolerant as its multiple webs, which are supported by the foam, provide redundant load paths, and, as stated above, the facesheets do not tend to delaminate from the core. The RCS preform can also be stitched prior to resin infiltration to further improve damage tolerance.

The primary application of the RCS concept to date has been in wind turbine blades, where the concept reduces cost and improves performance compared to balsa and PVC foam designs. Because cost is a primary driver in this application, glass fibers are typically used rather than carbon fibers. RCS is also

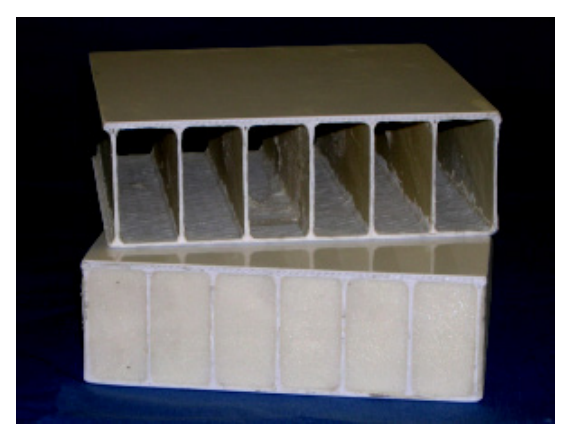

(a)

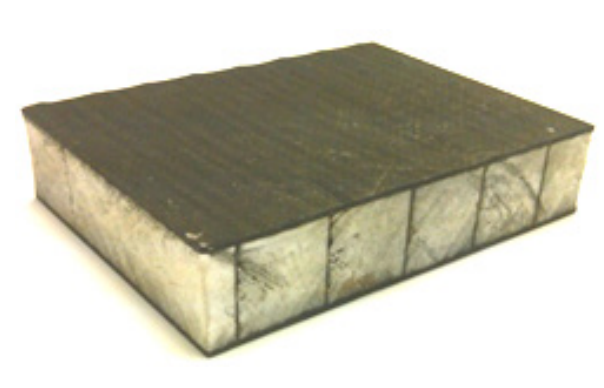

(b)

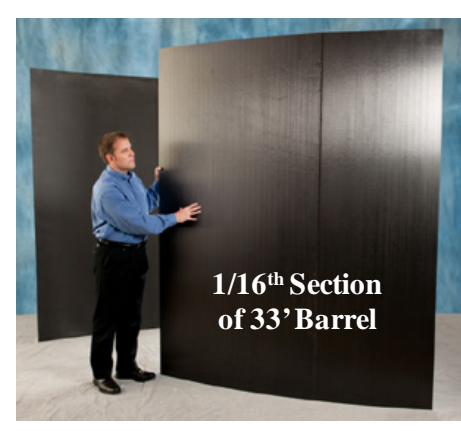

(c)

Figure 1.-(a) WebCore RCS panels with and without foam removed. (b) Typical RCS panel. (c) Large curved RCS panel infiltrated by Janicki. 
currently employed in marine structural applications, such as hulls, decks, bulk-heads, cockpit floors, hard tops, and fishing tower platforms. Additional non-aerospace applications include specialty shelters, high impact matting, and bridge decks. Aerospace applications for RCS include the ATK shroud boat tail demonstration article (Ref. 8), an impact-resistant turbine fan case designed and fabricated with NASA Glenn Research Center, and a weapons bay door for a Boeing UCAV, all of which were designed and manufactured using carbon fibers. In addition, preliminary designs of the NASA Crew Exploration Vehicle Crew Module (Ref. 5), the NASA Ares V shroud (Ref. 7), and the NASA Ares V interstage and intertank (Ref. 6) were reported using the RCS concept.

\subsection{Pultruded Rod Stitched Efficient Unitized Structure (PRSEUS) Panels}

The PRSEUS concept has been developed by Boeing as part of a decade long effort to bring stitched composite components into production (Refs. 4 and 9). As shown in Figure 2, PRSEUS features precured unidirectional composite rods at the top of the stringers that provides significant axial stiffness.

Transverse foam core sandwich frames provide stability to the stringers, which are accommodated with a pass through slot. The PRSEUS dry preform is assembled and stitched prior to resin infusion and oven curing. Stitching provides PRSEUS with a high level of damage tolerance as the stringers and frames do not delaminate from the facesheet and facesheet cracks tend to be deflected (Ref. 4). Example PRSEUS panels are shown in Figure 3.

Inclusion of this panel concept into HyperSizer presents several unique design features with respect to other panel types. First, this concept includes integrated transverse frames rather than relying on traditional skin stringer design with ring-frame beams. This allows the panel to efficiently handle biaxial loads, however, it makes this a challenging concept to optimize because the stringers and frames must be optimized simultaneously to obtain the lightest, most efficient structure. Second, this panel concept includes a very stiff pultruded rod stringer rather than a traditional flange. Early on, we recognized stability of this rod as an analysis challenge requiring a stiffener failure method not in present versions of HyperSizer. Finally, this panel concept, as opposed to more traditional designs has the ability to operate well into the postbuckling regime, and an analysis technique for robustly analyzing into this regime was needed so that PRSEUS panels could be efficiently sized to include postbuckling.

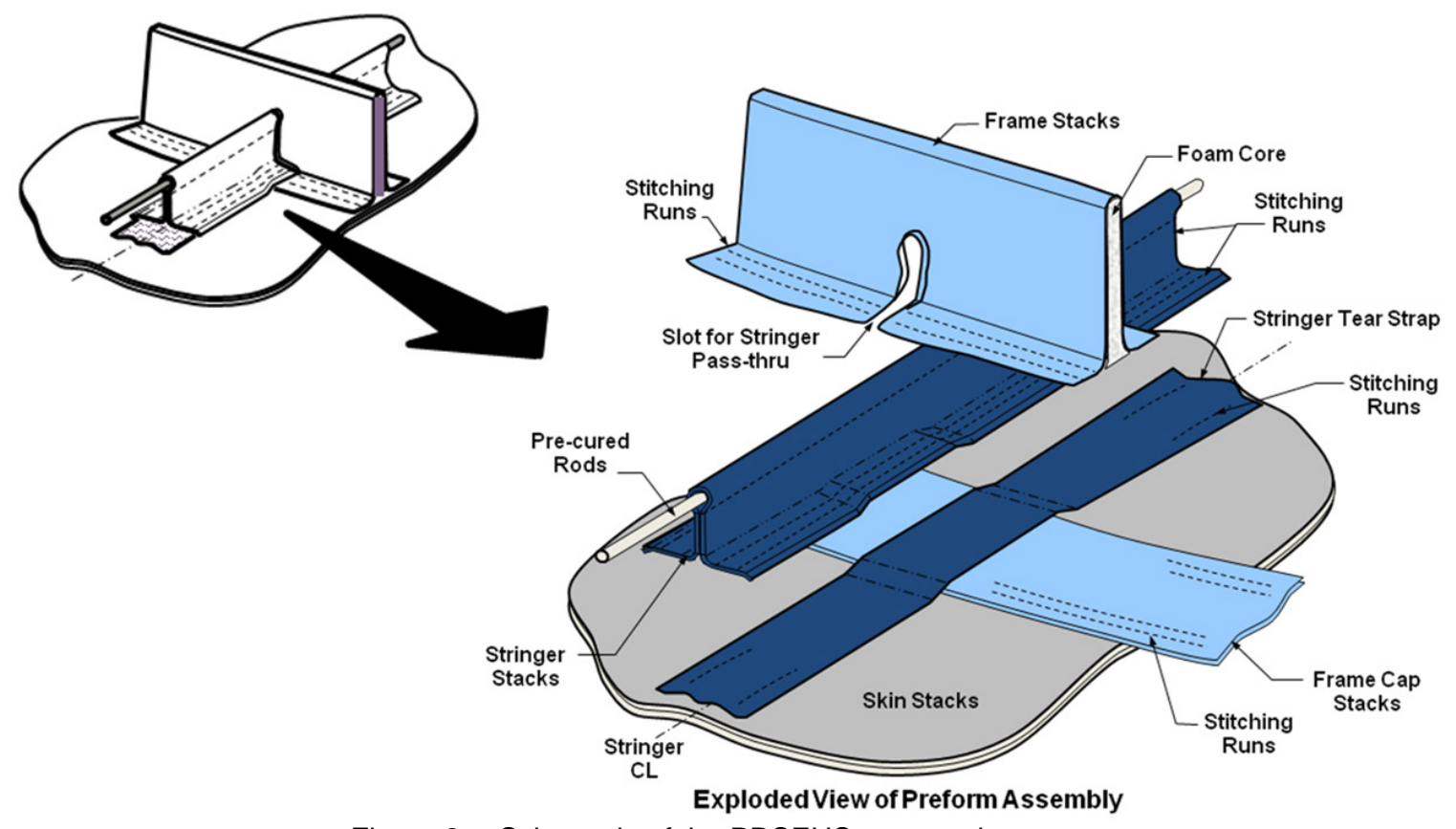

Figure 2.-Schematic of the PRSEUS structural concept. 

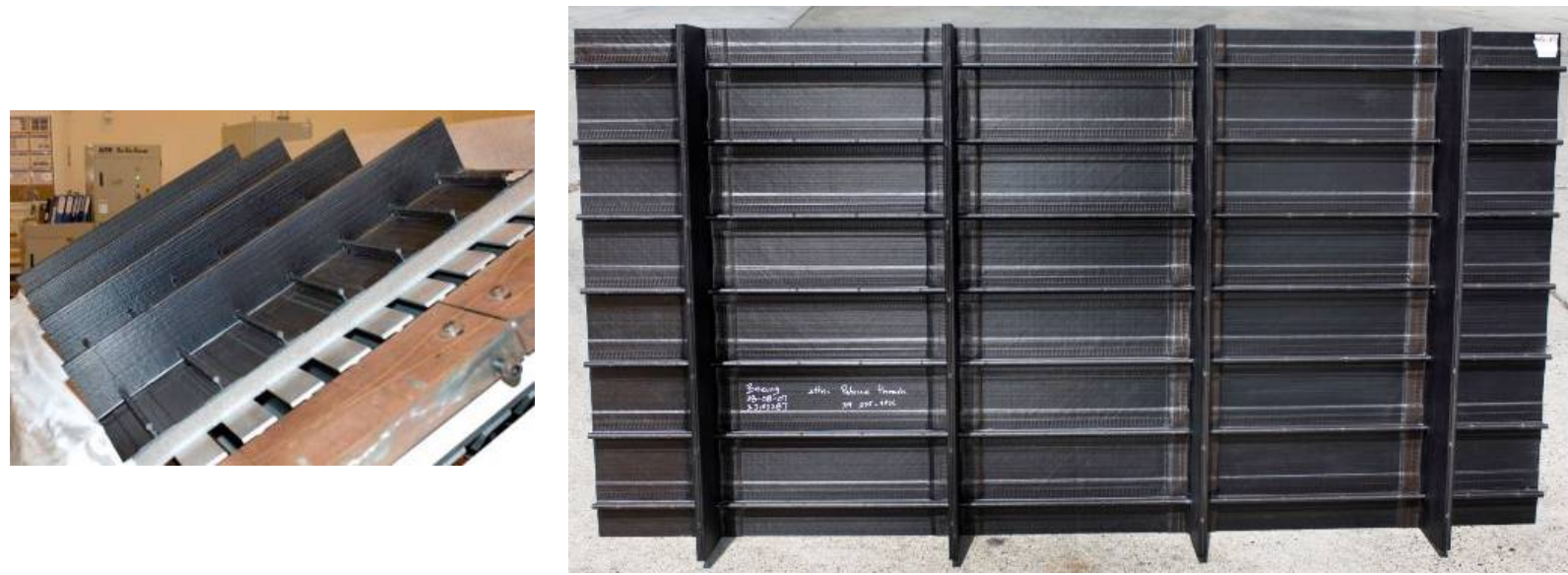

Figure 3.-Example PRSEUS panels.

\subsection{Design and Analysis Methods}

\subsection{Reinforced Core Sandwich (RCS) Panels}

RCS panels are similar to honeycomb and foam sandwich panels in that the primary function of the core is to separate the facesheets to increase the bending stiffness and to provide through-thickness strength and stiffness. In honeycomb and foam sandwich panels, it is typically assumed that the core does not contribute to the panel in-plane stiffness and strength. In the case of RCS, the composite material formed by the wrap layers does provide some contribution to the panel properties in the web direction (similar to a blade-stiffened sandwich panel). The variables associated with the design of an RCS panel include top facesheet thickness and material, the bottom facesheet thickness and material, the web thickness and material, the web spacing, the panel height, and the foam material (see Figure 4). The implementation of the concept in HyperSizer automatically adds half of the web material or layup to the top facesheet and half to the bottom facesheet to properly account for the wrap fibers, forming top and bottom face "combos”. Once the wrap layers are correctly combined with the top and bottom facesheets, HyperSizer determines the effective ABD stiffness terms of the RCS panel identically to the methods used for a blade-stiffened sandwich panel. That is, the contribution of the foam to the panel stiffness is ignored. The foam does, however, play an important role in the failure methods for RCS.

Table 1 summarized the failure modes observed for RCS panels and details of the method implemented to capture the mode. For composite strength, standard failure criteria are used at the ply level once ply level stresses and strains have been determined. To obtain these ply level stresses, it is

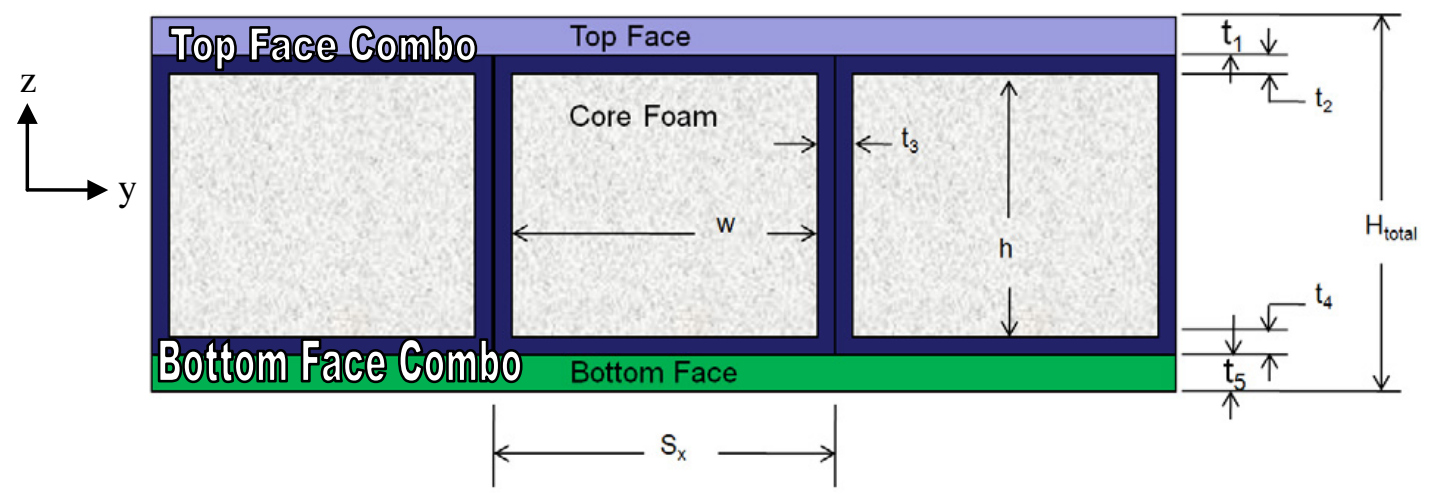

Figure 4.-Schematic of and RCS panel cross-section showing composition and design variables. 
assumed that the panel loads Ny, Nxy, My, and Mxy are reacted by the facesheet combos only, whereas, $\mathrm{Nx}, \mathrm{Mx}$, are reacted by the facesheet combos and the webs. Qy is reacted only by the foam. Qx is reacted by the foam and the webs, but due to orientation of the web, Qx enters as a local Nxy. The panel Qx is distributed to the foam and the web based on their relative stiffness and area. For shear failure of the foam, the Qx and Qy reacted by the foam are divided by the thickness to obtain the through-thickness shear stresses in the foam. These are directly compared to the allowables and also combined in a quadratic interaction criterion. If the panel is subjected to pressure, a through-thickness compressive stress is calculated for the foam based on distributing the pressure to the webs and the foam (again, based on their relative stiffnesses and areas) and compared to the foam crush allowable. For shear crimping, which is a short wave buckling mode caused by low core through-thickness shear stiffness (Ref. 1), the effective through-thickness shear stiffness of the core was calculated via a Voigt relation,

$$
G_{x z}^{e f f}=\frac{t_{w}}{S_{x}} G_{x y}^{w}+\left(1-\frac{t_{w}}{S_{x}}\right) G_{\text {foam }}
$$

where $t_{w}$ is the web thickness, $S_{x}$ is the stiffener spacing, $G_{x y}^{w}$ is the web effective in-plane shear modulus, and $G_{\text {foam }}$ is the shear modulus of the foam. This effective core shear stiffness is used in the shear crimping allowable equation in the web direction ( $x$-direction), whereas, in the $y$-direction, the foam shear stiffness is used. The effective shear stiffness of the core is also used in the HyperSizer panel buckling equations for RCS to calculate the transverse shear flexibility correction factor. For facesheet wrinkling, a similar Voigt-type equation is used to determine the effective core through-thickness crush stiffness for use in the sandwich facesheet wrinkling equations (Ref. 10).

TABLE 1.-BRIEF DESCRIPTION OF RCS PANEL FAILURE MODES

AND ASSOCIATED METHODS IMPLEMENTED WITHIN HyperSizer

\begin{tabular}{|c|c|c|}
\hline Mode & Objects(s) & Description/method \\
\hline $\begin{array}{l}\text { Composite } \\
\text { strength }\end{array}$ & Web, facesheet & $\begin{array}{l}\text { - Based on loads (N, M, Q) on panel } \\
\text { - Web acts as decoupled, but panel Q goes into web as web Nxy } \\
\text { - Foam assumed to only affect the Nxy in the web } \\
\text { - Many standard failure criteria (max stress/strain, Tsai-Wu, Hashin, LaRC03, etc.) } \\
\text { - Added localization to get Q distribution between web and foam }\end{array}$ \\
\hline Shear strength & Foam & $\begin{array}{l}\text { - Due to through-thickness shears on panel Qx, Qy } \\
\text { - Compare shear stress in foam to allowable } \\
\text { - Check Qx, Qy, quadratic interaction } \\
\text { - Added localization to get shear stress in foam }\end{array}$ \\
\hline Crushing & Core & $\begin{array}{l}\text { - Due to pressure crushing panel, through-thickness shear loads crushing core against } \\
\text { a flange } \\
\text { - Resulting stress, localized to foam, compared to core crush allowable } \\
\text { - Added localization of crush stress to foam }\end{array}$ \\
\hline Shear crimping & Core & $\begin{array}{l}\text { - Short wave buckling of panel due to low core stiffness } \\
\text { - Based on through-thickness shear moduli of core, no interaction } \\
\text { - Added homogenization of web/foam to get effective shear stiffness of core }\end{array}$ \\
\hline Panel buckling & Panel & $\begin{array}{l}\text { - Based on panel-level ABD and panel through-thickness shear stiffness } \\
\text { - Foam assumed to only affect through-thickness shear stiffness } \\
\text { - Added homogenization of web/foam to get effective shear stiffness of core }\end{array}$ \\
\hline Wrinkling & Facesheet & $\begin{array}{l}\text { - Local shortwave buckling of facesheet } \\
\text { - Classical method for sandwich panels } \\
\text { - Added homogenization of web/foam to get effective crush stiffness of core }\end{array}$ \\
\hline Local buckling & Web, facesheet & $\begin{array}{l}\text { - Standard HyperSizer method treats web and FS as plate with simple support on all } \\
\text { edges } \\
\text { - Does not include support provided by foam between webs and facesheets } \\
\text { - Added new method to HyperSizer based on buckling on elastic foundation models }\end{array}$ \\
\hline
\end{tabular}


For local buckling of the RCS web and facesheets, significant effort was required to develop viable methods for use in HyperSizer. This is because the main benefit of the foam material is to provide support for the web and facesheet against buckling. Thus this support must be accounted for in the HyperSizer methods to size RCS panels that are truly optimized. As such, the standard approach to local buckling of stiffened panels in HyperSizer were used, wherein the web and facesheets are treated as simply supported plates and the moments and coupling stiffness terms are ignored, with the addition of support provided by the foam. A Winkler (spring-like) foundation model, where a linear relation is assumed between the plate deflection and the pressure exerted by the foundation on the plate has been implemented. The standard anisotropic plate bending equation, with coupling stiffness terms assumed to be zero (Ref. 11), can then be written as,

$$
\begin{aligned}
D_{11} \frac{\partial^{4} w}{\partial x^{4}}+4 D_{16} \frac{\partial^{4} w}{\partial x^{3} \partial y}+2\left(D_{12}+\right. & \left.2 D_{66}\right) \frac{\partial^{4} w}{\partial x^{2} \partial y^{2}}+4 D_{26} \frac{\partial^{4} w}{\partial y^{3} \partial x} \\
& +D_{22} \frac{\partial^{4} w}{\partial x^{4}}+K w=N_{x} \frac{\partial^{2} w}{\partial x^{2}}+N_{y} \frac{\partial^{2} w}{\partial y^{2}}+2 N_{x y} \frac{\partial^{2} w}{\partial x \partial y}
\end{aligned}
$$

where the pressure has been written as a stiffness $K$ of the foundation (also known as the bedding constant) times the plate deflection, $w$. We consider the section of facesheet between the webs, or the webs themselves, to be infinite strips in shear as they are much longer in the web direction than between the webs. In compression, a finite plate is considered. To further simplify the problem, shear loading and a single compressive normal load component are considered as separate cases.

For an infinite strip subjected to shear loading, $N_{x y}=t$, as shown in Figure 5 under simply supported boundary conditions, Timoshenko's (Ref. 12) method is used where it is assumed that the buckled plate deflection is given by,

$$
w=A \sin \frac{\pi y}{b} \sin \frac{\pi}{s}(x-\alpha y)
$$

where $A$ is a constant, $b$ is the width of the strip, $s$ is the $x$-distance between buckling half-waves, and $\alpha$ is slope in $x-y$ coordinates of the buckling wave nodes. The terms $s$ and $\alpha$ must be determined. This deflection is shown in Figure 6.

To determine the approximate critical buckling load, the principal of minimum potential energy,

$$
\partial \Pi=\partial(U+V)
$$

is used, where the strain energy due to bending is given by,

$$
\begin{aligned}
U_{1}=\frac{1}{2} \iint\left[D_{11}\left(w_{, x x}\right)^{2}+2 D_{12}\left(w_{, x x}\right)\left(w_{, y y}\right)+D_{22}\left(w_{, y y}\right)^{2}\right. & \\
& \left.+4\left(D_{16} w_{, x x}+D_{26} w_{, y y}\right) w_{, x y}+4 D_{66}\left(w_{, x y}\right)^{2}\right] d x d y
\end{aligned}
$$

the strain energy due to the deformation of the elastic foundation is given by,

$$
U_{2}=\iint \frac{1}{2} K w^{2} d x d y
$$




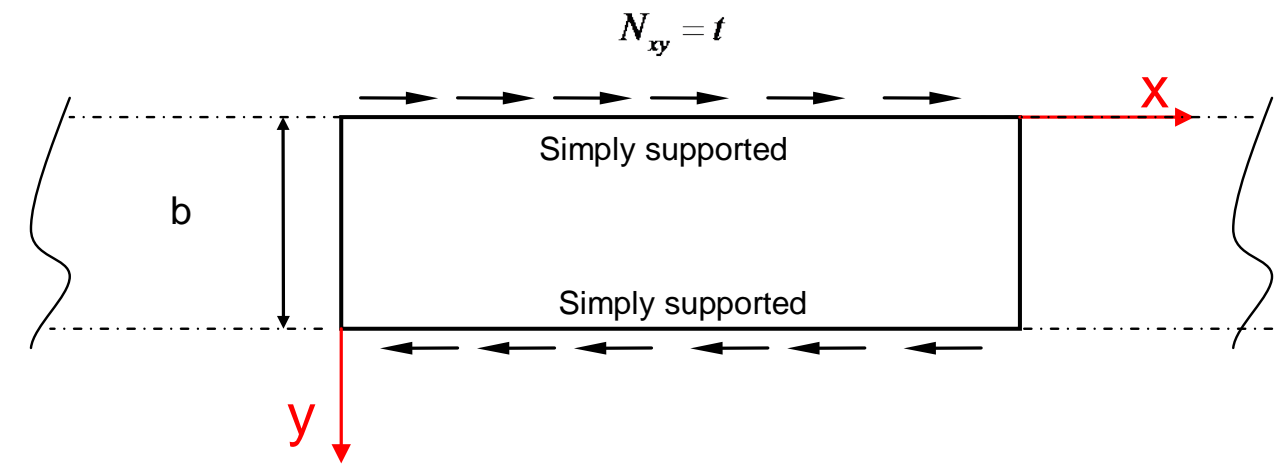

Figure 5.-Infinite strip used to model the webs or facesheet located between webs subjected to shear loading.

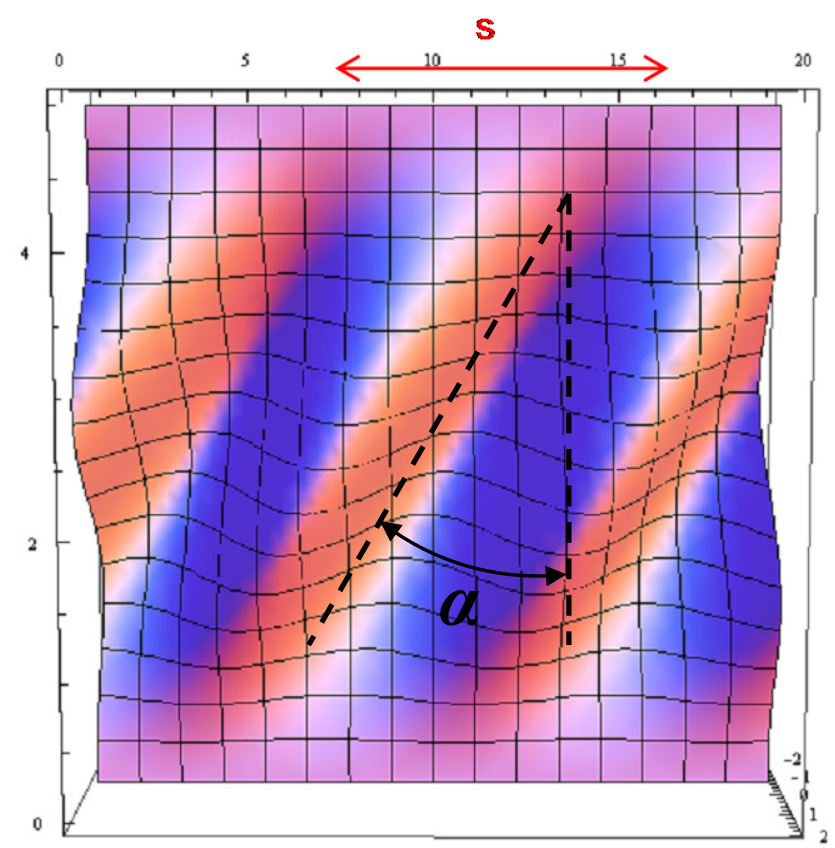

Figure 6.-Assumed buckled mode shape for infinite strip under simple support subjected to shear loading.

and the work done by the loads is given by,

$$
V=\frac{1}{2}\left[\iint N_{x}\left(W,,_{x x}\right)^{2}+N_{y}(W, y y)^{2}+2 N_{x y}(w, x)\left(w, y_{y}\right)\right] d x d y
$$

The deflection, Equation (3), is substituted into Equations (5), (6), and (7), which are integrated over the area of a buckling half-wave $(y=0, \mathrm{~b} ; x=0, s)$. The variation of the total potential energy, Equation (4), is minimized by setting the second derivative of $U_{1}+U_{2}+V$ with respect to $A$ to zero. This can be solved for the critical shear buckling load, $t_{c r}$, 


$$
\begin{aligned}
t_{c r}=\frac{\left(D_{12}+2 D_{66}\right) \pi^{2}}{b^{2} \alpha}+\frac{3 b^{2} \pi^{2} \alpha\left(-2 D_{26}+D_{22} \alpha\right)}{b^{4} \alpha} \\
+\frac{\left(\sqrt{-b^{4} K-D_{22} \pi^{4}}\right) \sqrt{-b^{4}\left(D_{11}+\alpha\left(-4 D_{16}+\alpha\left(2 D_{12}+4 D_{66}+\alpha\left(-4 D_{26}+D_{22} \alpha\right)\right)\right)\right)}}{b^{4} \alpha}
\end{aligned}
$$

where an expression for the variable, $s$, has been determined by minimizing $t_{c r}$ with respect to this variable. Equation (8) still contains the variable $\alpha$, which is determined by numerically minimizing $t_{c r}$ with respect to this variable.

For compressive loading, a finite plate simply supported on all edges is considered (Figure 7). The assumed form of the buckled deflection that satisfies Equation (2) is,

$$
w=A \sin \left(\frac{\pi \mathrm{x}}{\mathrm{a} / \mathrm{n}}\right) \sin \left(\frac{\pi \mathrm{y}}{\mathrm{b}}\right)
$$

(see Figure 8) where $\mathrm{n}$ is the number of buckling half-waves in the $x$-direction. Following a similar procedure to that used in the case of shear loading, the critical normal buckling load can be determined as,

$$
P_{c r}=\frac{-2 n \pi\left(2 a^{2} b^{2}\left(D_{12}+2 D_{66}\right) n^{2} \pi^{4}+b^{4} D_{11} n^{4} \pi^{4}+a^{4}\left(b^{4} K+D_{22} \pi^{4}\right)\right)}{a^{2} b^{4} n^{2} \pi^{2}(2 n \pi)}
$$

In HyperSizer, the critical $\mathrm{N}_{\mathrm{xy}}$ load for the RCS facesheet and web is determined from Equation (8), while the critical $\mathrm{N}_{\mathrm{x}}$ and $\mathrm{N}_{\mathrm{y}}$ loads are determined individually from Equation (10). Then, to determine failure under combined loads, the following interaction equation is used,

$$
\sqrt{\left(\frac{N_{x}}{N_{x}^{c r}}\right)^{2}+\left(\frac{N_{y}}{N_{y}^{c r}}\right)^{2}+\left(\frac{N_{x y}}{N_{x y}^{c r}}\right)^{2}}=1
$$

where the superscript $c r$ denotes a critical load, and the load terms without superscripts are the web or facesheet loads determined by HyperSizer.

To evaluate Equations (8) and (11), a value for the foundation stiffness, or bedding constant $(K)$ is needed. Two methods for determining the value of $K$ have been implemented in HyperSizer. The effective stiffness approach is based on the modulus and width of the foam. For the web, with two-sided support by the foam (Figure 4), the effective stiffness is given by (Ref. 13),

$$
K=E_{\text {foam }} / h_{\text {core }}
$$

and for the facesheet, with one-sided support,

$$
K=E_{\text {foam }} /\left(2 S_{x}\right)
$$

The second approach was suggested by Hetenyi (Ref. 13), with the value for the web given by,

$$
K=2\left[0.28 E_{\text {foam }}\left(E_{\text {foam }} / D_{11}^{\text {web }}\right)^{\frac{1}{3}}\right]
$$

and for the facesheet,

$$
K=0.28 E_{\text {foam }}\left(E_{\text {foam }} / D_{11}^{F S}\right)^{\frac{1}{3}}
$$




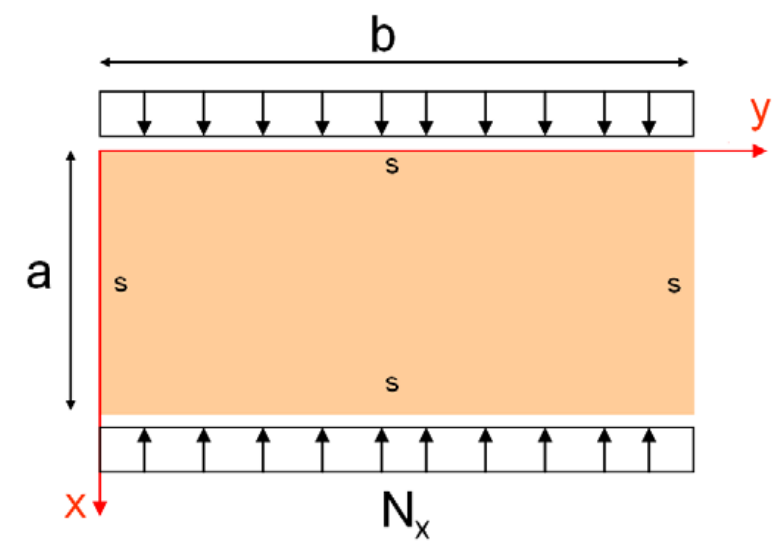

Figure 7.-Finite plate used to model buckling of RCS webs and facesheets under normal loading.

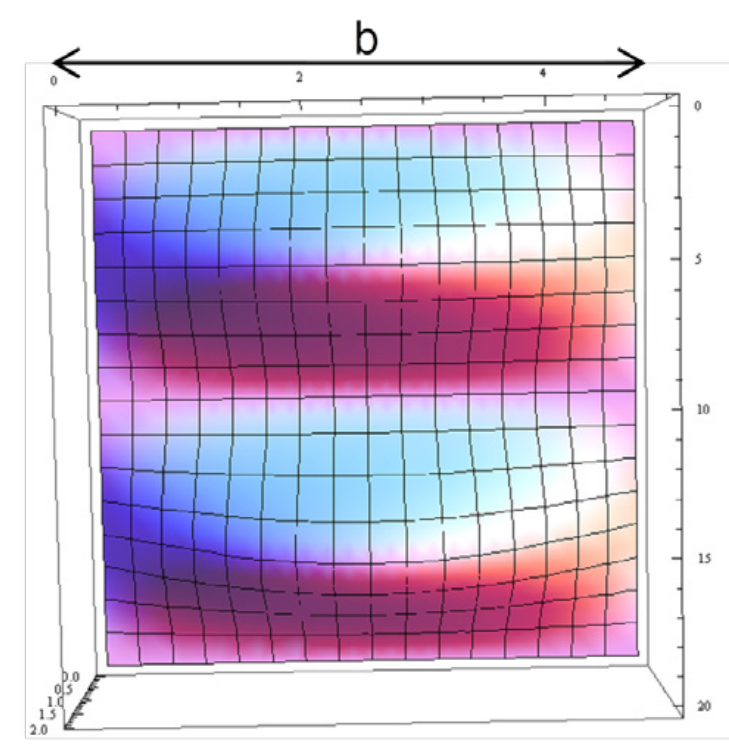

Figure 8.-Assumed buckling mode shape for finite simply supported plate under uniaxial compressive load.

\subsection{Pultruded Rod Stitched Efficient Unitized Structure (PRSEUS) Panels}

The analysis methods specific to PRSEUS fall within two major categories. The first is thermoelastic formulation of the entire panel 3D cross-section into a 2D planar equivalent representation quantified with fully coupled terms in the 6x6 matrix. This part of the analysis doesn't receive as much fanfare as does the other aspect which is failure prediction. However, accurate failure prediction could not take place without accurately representing the elastic response of the panel to any general loading condition.

The second general category of analysis is failure prediction. HyperSizer already had many of the failure methods needed to analyze the PRSEUS panel, however, two types of failure were identified as missing for PRSEUS panel analysis, these were local postbuckling of the facesheet and torsional buckling of the panel stiffener. The latter of these is especially important to predict stability of the stiffening rod. Analysis methods accounting for these failure methods were developed and verified against FEA as part of the PRSEUS panel development. 

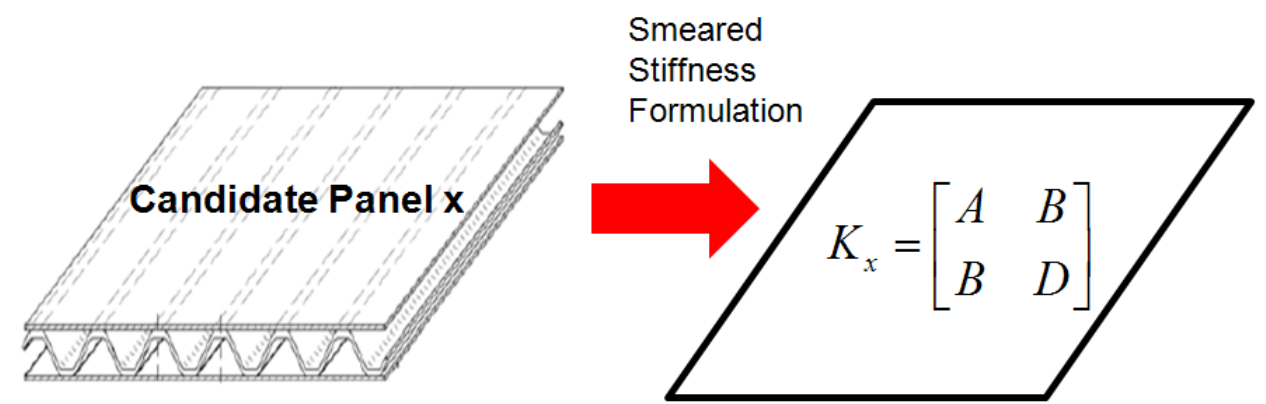

Figure 9.-Schematic of the HyperSizer generating an equivalent panel stiffness from a candidate panel design.

\subsubsection{Thermoelastic Formulation}

The first step in characterizing any HyperSizer panel concept is in formulating the strain response of a panel to an applied load or thermal environment. All HyperSizer failure analysis is built on this foundation. HyperSizer analyzes stiffened panels composed of arbitrary composite laminates through stiffener homogenization, or "smearing". The result is an effective constitutive equation for the stiffened panel that is suitable for use in a full vehicle-scale finite element analysis. The thermoelastic formulation of the PRSEUS panel extends existing methods for all other panel types.

As shown in Figure 9, for a give candidate panel design, HyperSizer generates a panel-level stiffness (constitutive equation). With this stiffness, HyperSizer applies the panel loads $\left(N_{x}, N_{y}, M_{x}\right.$, etc.) to get the panel strains. With the panel strains, HyperSizer reverses the smearing process to back out the loads in each object.

The smearing process is done by extending classical lamination theory (CLT) to stiffened panels. The thermoelastic formulation of a panel takes on the form:

$$
\left[\begin{array}{l}
\mathbf{N} \\
\mathbf{M}
\end{array}\right]=\left[\begin{array}{ll}
\mathbf{A} & \mathbf{B} \\
\mathbf{B} & \mathbf{D}
\end{array}\right]\left[\begin{array}{l}
\boldsymbol{\varepsilon} \\
\mathbf{\kappa}
\end{array}\right]-\left[\begin{array}{l}
\mathbf{N}^{T} \\
\mathbf{M}^{T}
\end{array}\right]
$$

where $\mathbf{N}$ and $\mathbf{M}$ are the panel level forces, $\boldsymbol{\varepsilon}$ and $\boldsymbol{\kappa}$ are the panel level strains and curvatures respectively and $\mathbf{N}^{T}$ and $\mathbf{M}^{T}$ are the panel level thermal forces and moments. The ABD matrix is the classical panelstiffness matrix from CLT relating panel resultant forces and moments to strains and curvatures. The same assumptions used in CLT apply to the HyperSizer formulation. These are sometimes referred to as the Kirchhoff assumptions with the major assumption being that plane sections remain plane after bending. HyperSizer's general thermoelastic formulations for representing stiffened panels as an effective ABD representation has been presented in some detail in previous papers (Refs. 14 and 15).

The overall ABD matrix for the panel can be derived by determining the A, B and D contributions of each constituent at the reference plane of the panel and simply adding these contributions. In other words,

$$
\begin{aligned}
& \mathbf{A}_{\text {panel }}=\mathbf{A}_{F S / \text { Flange }}+\mathbf{A}_{\text {Rod }}+\mathbf{A}_{\text {Stringer }}+\mathbf{A}_{\text {Frame }} \\
& \mathbf{B}_{\text {panel }}=\mathbf{B}_{F S / \text { Flange }}+\mathbf{B}_{\text {Rod }}+\mathbf{B}_{\text {Stringer }}+\mathbf{B}_{\text {Frame }} \\
& \mathbf{D}_{\text {panel }}=\mathbf{D}_{F S / \text { Flange }}+\mathbf{D}_{\text {Rod }}+\mathbf{D}_{\text {Stringer }}+\mathbf{D}_{\text {Frame }}
\end{aligned}
$$

Several extensions to HyperSizer's methods were required to extend the HyperSizer panel formulation to the PRSEUS Panel concept. These extensions included the stiffness contributions of the flange and facesheet overlaps of both the stringers and frames, and the stiffness contribution of the unidirectional rod. 


\subsubsection{Stiffness Contribution of the Flange and Facesheet Overlaps}

The complete derivation of the stiffness contribution of the flange and facesheet overlap is beyond the scope of this paper; however the assumptions that go into this derivation are as follows. The flange and facesheet contribution to the overall stiffness of the panel is determined by combining the flange and facesheet into a single smeared stiffness. The equivalent, generalized stiffness terms are used to compute the average panel response, in terms of strains $\left(\varepsilon_{i}\right)$ and curvatures $\left(\kappa_{i}\right)$. From these average values identified at the panel's reference plane, the strains and curvatures of each individual analysis object can be determined. This approach is straightforward for panel response in the longitudinal direction where the stiffener is continuous. However, in the transverse direction (perpendicular to the stiffener) the stiffness is discontinuous, as it changes abruptly from only the skin, to the combined skin and flange. Consider the panel shown Figure 10(a) and the corresponding response to transverse loading (Figure 10(b)). In HyperSizer, the panel is formulated by identifying regions or "segments", determining the ABD matrix for each segment and then combining these segments to form effective ABD matrices for the overall panel. In the case of the PRSEUS stringer flange/facesheet, three segments are defined. Segment 1 is the open span facesheet laminate, Segment 6 is the combination of the facesheet and flange, and Segment 8 is the combination of facesheet/flange with the open span.

It is incorrect to assume that the average panel strain and the strain of the local objects are the same, meaning the object forces must be different.

$$
\begin{array}{cl}
\varepsilon_{y[1]}=\varepsilon_{y[6]}=\varepsilon_{y[8]} & \Rightarrow \text { Wrong! } \\
N_{y[1]} \neq N_{y[6]} \neq N_{[8]} & \Rightarrow \text { Wrong! }
\end{array}
$$

However, the load path from one edge of the panel to the other edge of the panel must go through both the [1] and [6] objects. The HyperSizer formulation resolves this consistently by satisfying the object loads such that

$$
\begin{array}{ll}
N_{y[1]}=N_{y[6]}=N_{y[8]} & \Rightarrow \text { Correct } ! \\
\varepsilon_{y[1]} \neq \varepsilon_{y[6]} \neq \varepsilon_{y[8]} & \Rightarrow \text { Correct } !
\end{array}
$$

(a)

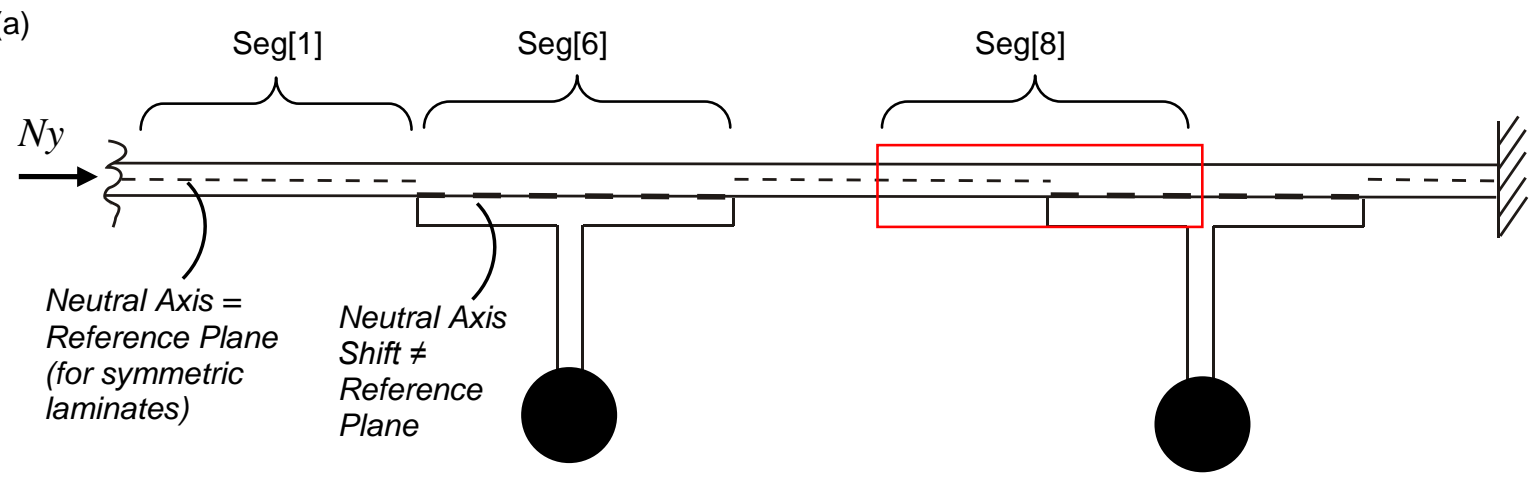

(b)

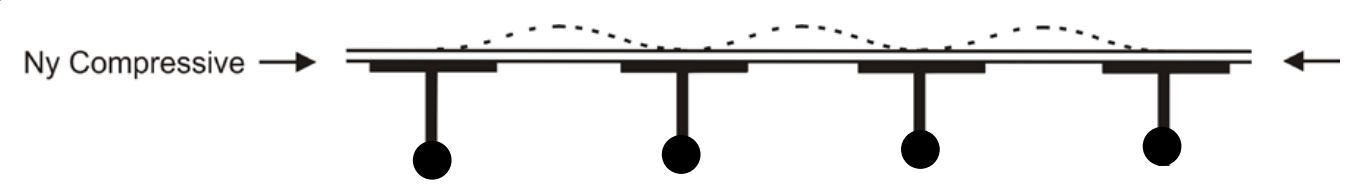

Figure 10.-(a) Definition of segments in a PRSEUS panel. (b) Deformation in response to transverse compression loading. 




Figure 11.-Depiction of iso-strain conditions for a layered panel segment.

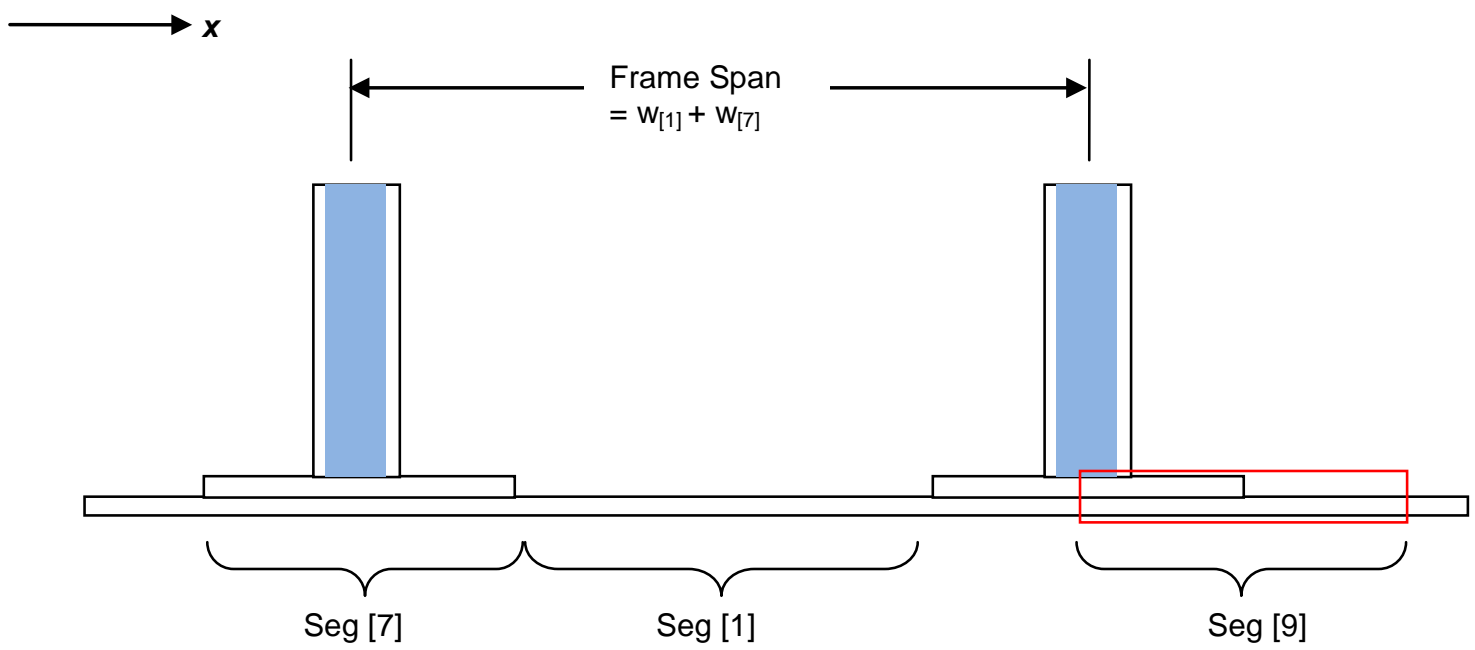

Figure 12.-Definition of segment 9 for a PRSEUS panel.

In the $\mathrm{x}$ direction (along the stiffener), the assumption is that entire panel strains as a unit (iso-strain), see Figure 11, which gives:

$$
\begin{gathered}
\varepsilon_{x[1]}=\varepsilon_{x[6]}=\varepsilon_{x[8]} \\
N_{x[8]} \neq N_{x[1]} \neq N_{x[6]}
\end{gathered}
$$

For the PRSEUS panel, a facesheet/flange segment exists not only for the stringer flange, but also for the frame flange object. We call this combination "Segment 9", see Figure 12. In this case, we formulate the combination object in exactly the same way except that in this case we assume iso-strain in the $y$ direction, rather than in the $\mathrm{x}$ direction.

Therefore, we have the following assumptions:

$$
\begin{aligned}
& N_{x[1]}=N_{x[7]}=N_{x[9]} \quad \Rightarrow \text { Correct! } \\
& \varepsilon_{x[1]} \neq \varepsilon_{x[6]} \neq \varepsilon_{x[9]} \quad \Rightarrow \text { Correct } !
\end{aligned}
$$

These assumptions for the stringers and flanges lead to a smeared equivalent ABD matrix which consistently represents the entire facesheet along with both the stringer and frame flange combos. 


\subsubsection{Stiffness Contribution of the Stiffening Rod}

The stiffening rod is an analysis object which is new to HyperSizer analysis, see Figure 13. The inclusion of a stiffening rod is a straightforward derivation assuming that the rods act only in the axial (i.e., $\mathrm{x}$ ) direction. The expression for force in a single stiffening rod is simply a function of the area of the rod and the axial modulus of elasticity.

$$
F_{\text {Rod }}=\left[E_{\text {Rod }}^{\text {Axial }} A_{\text {Rod }}\right] \varepsilon
$$

The force per unit length $\left(N_{x}\right)$ exerted by all of the rods on the stiffened panel is the force on one rod divided by the stringer spacing, $\mathrm{S}$.

$$
N_{\text {Rod }}=\left[\frac{E_{\text {Rod }}^{\text {Axial }} A_{\text {Rod }}}{S}\right] \varepsilon
$$

The term in brackets acts as an "A" membrane stiffness term. A similar expression can be found for the " $\mathrm{D}$ " bending contribution of the rod. The B membrane bending coupling of the rod is assumed to be zero. The contribution to the overall panel of the rods (in the reference plane of the rod) takes on the form:

$$
\mathbf{A}_{\text {Rod }}^{0}=\frac{E_{\text {Rod }}^{\text {Axial }} A_{\text {Rod }}}{S}\left[\begin{array}{lll}
1 & 0 & 0 \\
0 & 0 & 0 \\
0 & 0 & 0
\end{array}\right] \mathbf{B}_{\text {Rod }}^{0}=\mathbf{0} \quad \mathbf{D}_{\text {Rod }}^{0}=\frac{E_{\text {Rod }}^{\text {Axial }} I_{\text {Rod }}^{y y}}{S}\left[\begin{array}{lll}
1 & 0 & 0 \\
0 & 0 & 0 \\
0 & 0 & 0
\end{array}\right]
$$

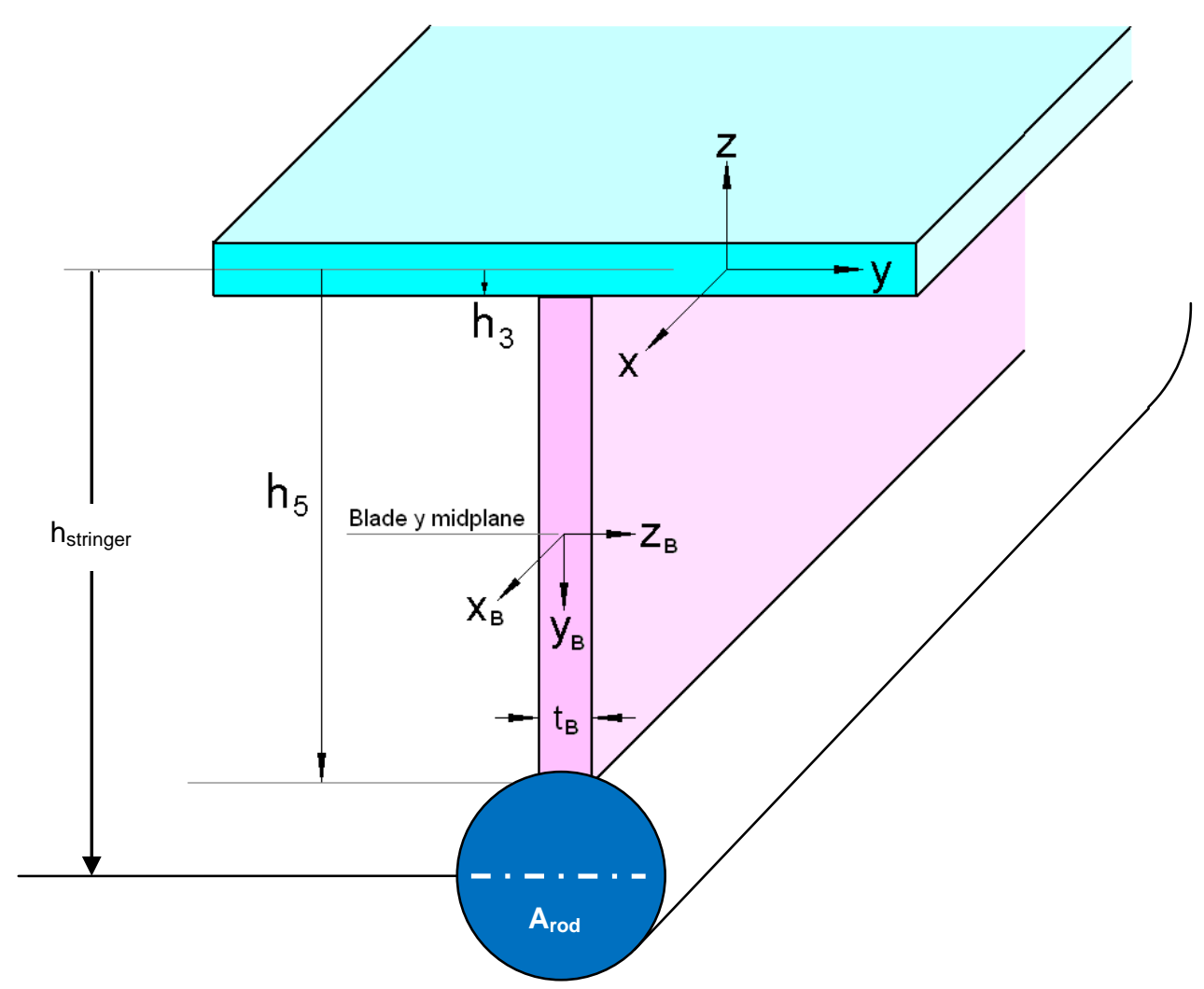

Figure 13._PRSEUS panel stringer notation and dimensions. 
Finally the contribution of the rod is transformed into the panel reference coordinate system using the parallel axis theorem so that it can be added to the overall panel ABD matrix.

$$
\mathbf{A}_{\text {Rod }}=\mathbf{A}_{\text {Rod }}^{0} \quad \mathbf{B}_{\text {Rod }}=\left(h_{\text {stringer }}\right) \mathbf{A}_{\text {Rod }}^{0} \quad \mathbf{D}_{\text {Rod }}=\mathbf{D}_{\text {Rod }}^{0}+\left(h_{\text {stringer }}\right)^{2} \mathbf{A}_{\text {Rod }}^{0}
$$

\subsubsection{Failure Analyses}

The failure methods that have been identified as applicable to the PRSEUS concepts and are included in the HyperSizer PRSEUS panel analysis capability are described in Table 2.

TABLE 2.-BRIEF DESCRIPTION OF PRSEUS PANEL FAILURE MODES AND ASSOCIATED METHODS IMPLEMENTED WITHIN HyperSizer

\begin{tabular}{|c|c|c|}
\hline Mode & Component(s) & Description/method \\
\hline Panel buckling & Panel & $\begin{array}{l}\text { - Based on panel-level smeared ABD Stiffness Matrix and panel Transverse } \\
\text { Shear Flexibility (TSF) } \\
\text { - Numerical Raleigh Ritz and closed-form solutions for panel buckling of curved } \\
\text { or flat panels in uniaxial, biaxial, and/or shear loading }\end{array}$ \\
\hline Crippling & Panel & $\begin{array}{l}\text { - Based on loads on overall panel (N, M, Q) } \\
\text { - Semi-empirical method that uses load distribution in various objects such as } \\
\text { facesheet, flanges, web } \\
\text { - Predicts overall panel collapse after local buckling of a portion of the panel } \\
\text { concentrated in the remaining stable cross-section exceeds material ultimate } \\
\text { strength }\end{array}$ \\
\hline $\begin{array}{l}\text { Johnson-Euler } \\
\text { buckling-crippling } \\
\text { interaction }\end{array}$ & Panel & $\begin{array}{l}\text { - This method combines the effects of panel buckling and crippling to predict } \\
\text { ultimate failure load of the panel }\end{array}$ \\
\hline Composite strength & Web, facesheets & $\begin{array}{l}\text { - Based on loads (N, M, Q) on panel } \\
\text { - Panel level Transverse Shear forces Qx, Qy goes into web and frames as in- } \\
\text { plane shear force, Nxy } \\
\text { - Many standard failure criteria (max stress/strain, Tsai-Hill, Hoffman, etc.) }\end{array}$ \\
\hline Local buckling & Web, facesheets & $\begin{array}{l}\text { - Objects modeled as rectangular plates with simple support on all edges } \\
\text { - Fourier series solution of plate ODE, including Ny/Nx ratio } \\
\text { - Shear buckling as a separate calculation - combined with biaxial buckling } \\
\text { through quadratic interaction } \\
\text { - Many times this failure mode is not considered to be catastrophic }\end{array}$ \\
\hline Local postbuckling & Facesheets & $\begin{array}{l}\text { - Redistributes load from buckled (ineffective) portion of panel to a calculated } \\
\text { "effective” width. } \\
\text { - PRSEUS panel shown (both in analysis and test) to carry substantial } \\
\text { postbuckling loads } \\
\text { - Predicts failure in postbuckling due to crippling, material strength, panel } \\
\text { buckling }\end{array}$ \\
\hline Torsional buckling & Panel, stiffeners & $\begin{array}{l}\text { - Failure of the panel due to "tipping" of the stiffener under compressive load. } \\
\text { Considered to be an ultimate failure. } \\
\text { - Calculates stability of stiffener by modeling the interface between stiffener and } \\
\text { facesheet as a combination of linear and rotational spring constants } \\
\text { - Closed-form physics based method originally developed for metallic fastened } \\
\text { panels extended to composite bonded panels including PRSEUS configuration }\end{array}$ \\
\hline
\end{tabular}

\subsubsection{Instability Modes Applicable to PRSEUS}

The general instability modes that are applicable to the PRSEUS Panel Concept and are included in the HyperSizer software are described in Table 3. 
TABLE 3.-DETAILS OF PRSEUS INSTABILITY MODES

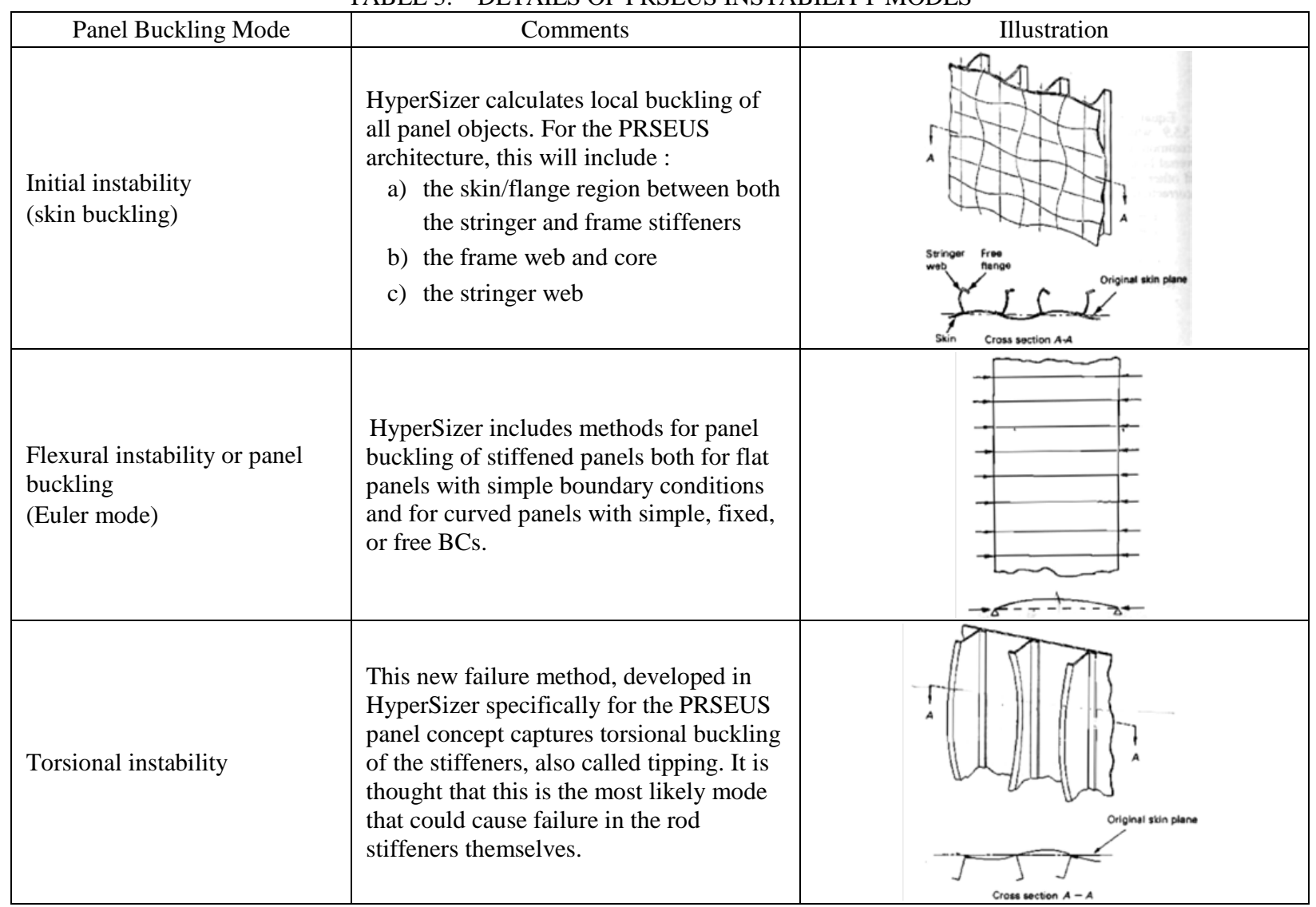

\subsubsection{Local Buckling}

The local buckling methods used by HyperSizer assume that panel objects behave like flat plates from a buckling perspective. HyperSizer uses closed-form methods to solve for local buckling of these objects so that the buckling solutions can be included in the full panel optimization process.

There are three applicable local buckling objects in the PRSEUS panel concept.

1. Local buckling of the stringer web (Figure 14(a)). The assumption is made that the facesheet and stiffener rod act as perfect simple (or pinned) boundary conditions on the stringer web.

2. Local buckling of the frame web/foam (Figure 14(b)). These structures have a high bending stiffness due to their sandwich-like behavior, however they are generally spaced farther apart (i.e., 20 in. in the baseline panel) meaning that they will be more highly loaded in a panel biaxial loading scenario. In addition, these panels will be treated as having a "free" boundary, rather than having all edges simply supported. This will also adversely affect the buckling characteristics.

3. Local buckling of the "Spacing Span" (Figure 15). The spacing span is the region between the stiffeners which includes both the bare facesheet and the bonded flange regions. The assumption is that local buckling waves between stiffeners will not be restricted to just the facesheet, but will include the stiffeners as well.

HyperSizer draws a distinction in the software between two objects called respectively "Open Span” and "Spacing Span". The open span is the region of bare facesheet between the flanges of the stiffened panel. For stiffened panels with bonded stiffeners, unless the facesheets are extremely thin compared to the flanges, a local buckling wave will not occur in the open span, but rather in the spacing span, which is a region that goes from stiffener to stiffener. This is assumed to be the case for the PRSEUS panel concept. 


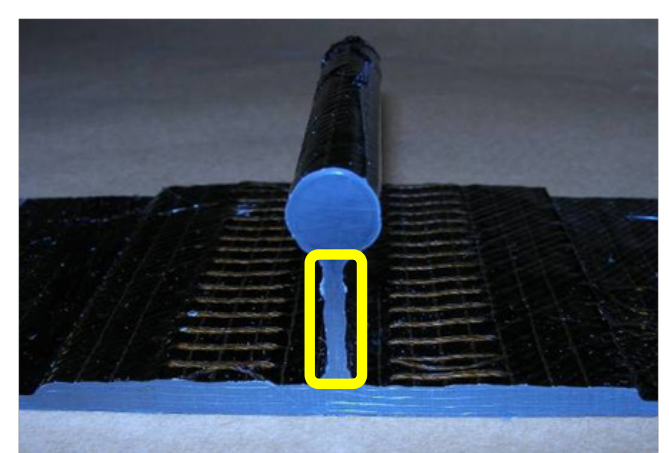

(a)

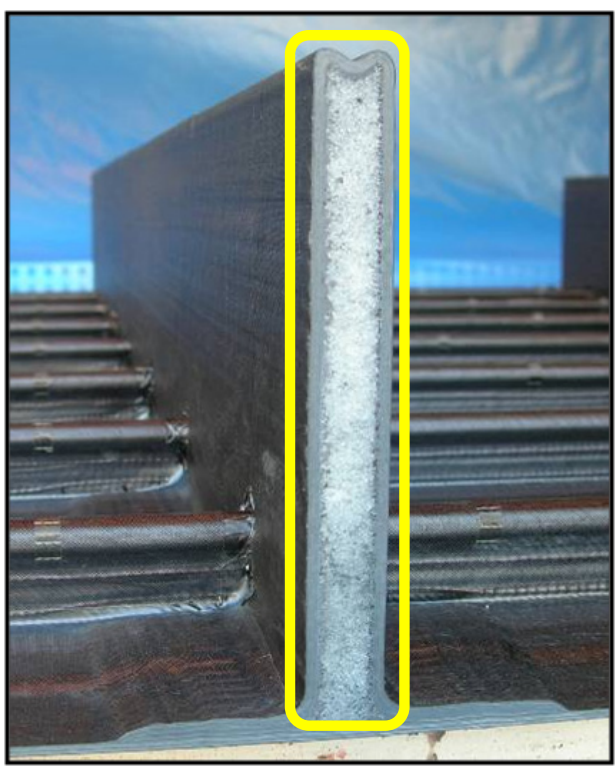

(b)

Figure 14.-Local buckling objects for the PRSEUS panel: a) stringer web b) frame web and foam.
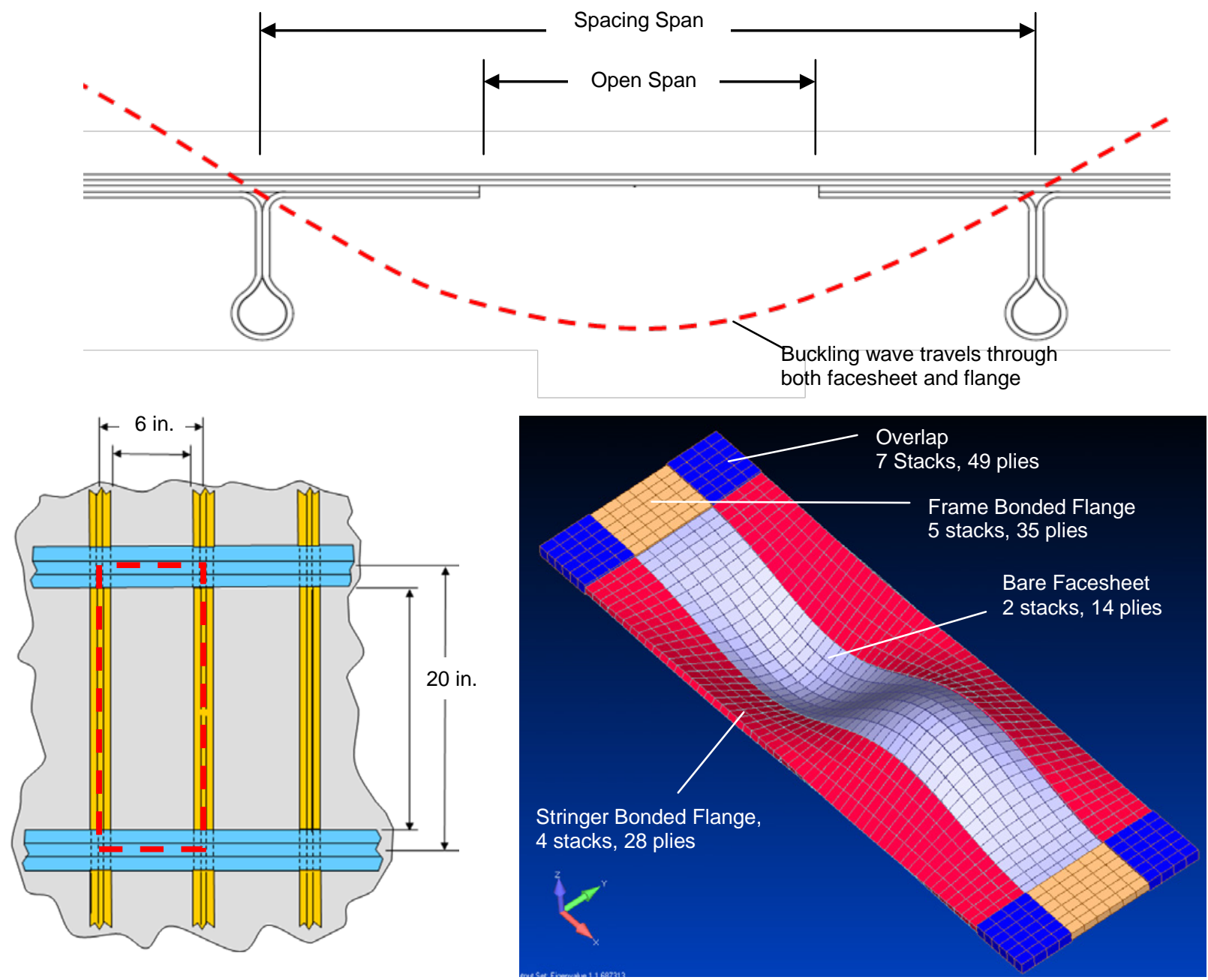

Figure 15.-Illustration of PRSEUS spacing span buckling. 




Figure 16.-A PRSEUS stiffened panel with a depicted local buckling mode shape.

\subsubsection{Facesheet Postbuckling}

The first failure mode for most stiffened panels (including PRSEUS) is usually initial buckling of the skin between stiffeners (Figure 16). After initial skin buckling, the stiffened panel can support additional load. Allowing the skin to buckle at operational loads requires a local postbuckling analysis capability.

As an example, consider the PRSEUS stiffened panel cross-section of Figure 17 loaded in uniform compression. At the onset of skin buckling (local buckling) the analysis is linear elastic, and all of panel objects such as the skin, stiffener web, and stiffener flange are loaded uniformly. The average level of stress is depicted as the horizontal dashed line in Figure 17(c). As additional load is applied to the panel, the buckled skin between stiffeners remains at the same stress (constant bifurcation load) and the additional load is picked up by the stiffener and the remaining effective width, $\boldsymbol{b}_{\boldsymbol{e}}$ of the skin. As more load is applied, the effective width becomes more narrow and the remaining stable cross-section of skin and stringer carries higher load until either the material reaches compressive yield, the strip-column buckles, or the stiffener cripples. The actual state of stress distribution of Figure 17(d) is represented in the HyperSizer postbuckling method as a rectangular step function, as shown in Figure 17(e). For the PRSEUS panel, not only does the stringer cross-section continue to carry load in postbuckling, but the transverse frame cross-section carries additional load as well.

Local postbuckling of a span is permissible if the panel can be shown to support additional load beyond the first occurrence of buckling (bifurcation point), without strength failure or collapse from buckling or cross-section crippling. In traditional metallic aerospace designs, the spans are allowed to local buckle even at limit loads, but normally not at loads below a prescribed level, such as 0.5 Design Limit Load (DLL). Postbuckling of composite structures are less common because of the possibility of stiffener debonding in the presence of buckling waves. However, PRSEUS' inclusion of stitching between the facesheet and stringer flange enhances the bond strength making postbuckling more feasible than in traditional composite-stiffened designs. The local postbuckling method implemented in HyperSizer is discussed in more detail in References 16 and 17.

\subsubsection{Torsional Buckling}

An additional analysis method developed for the PRSEUS concept is torsional buckling of the stringer. This failure mode occurs when the stringer, which is stabilized by its connection to the facesheet, buckles out-of-plane, also known as stiffener "tipping." This buckling mode in-turn reduces the bending stiffness of the overall panel. An antisymmetric torsional buckling mode for PRSEUS is shown in Figure 18.

Stiffener torsional buckling can be analyzed with finite element solvers. However, such analyses are computationally expensive and are not feasible options when rapid sizing of a stiffened panel is required. The number of iterations involved in optimization requires a rapid but accurate method. 
A

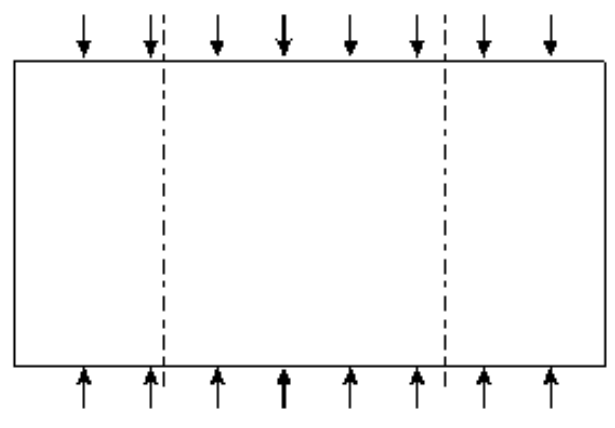

B
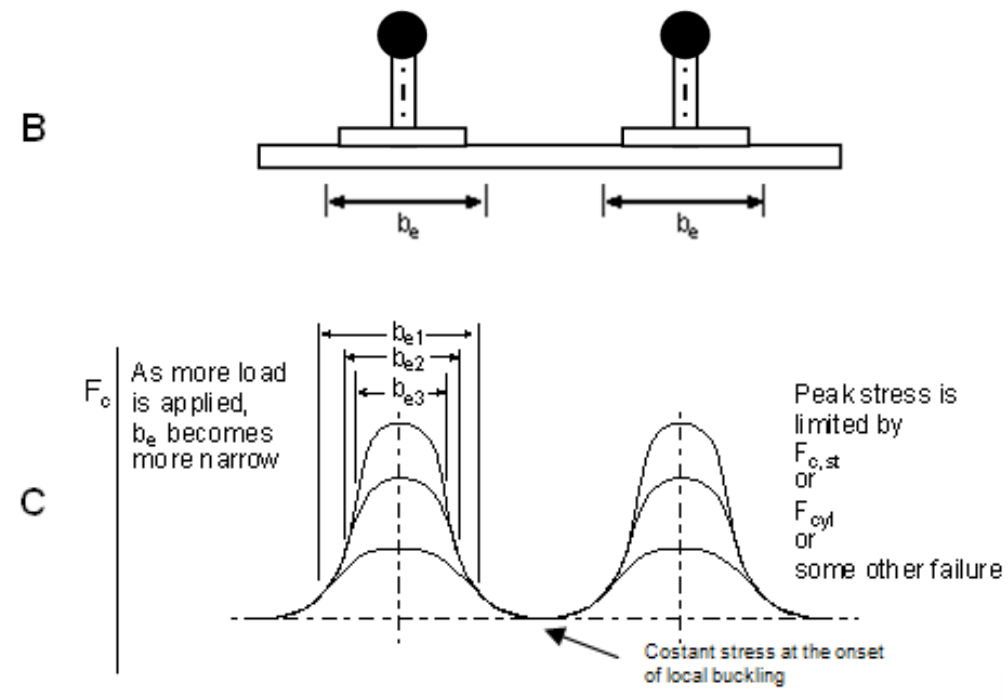

D
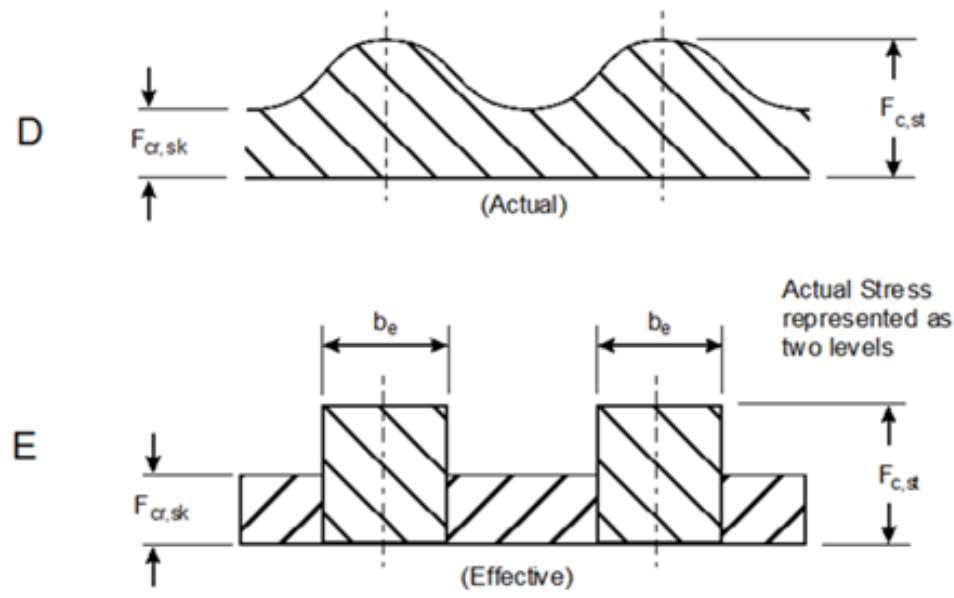

Figure 17.-The effective width of the facesheet is included with the stiffener in the calculation of remaining panel stable cross-section. As load is increased the remaining effective width becomes narrower. 


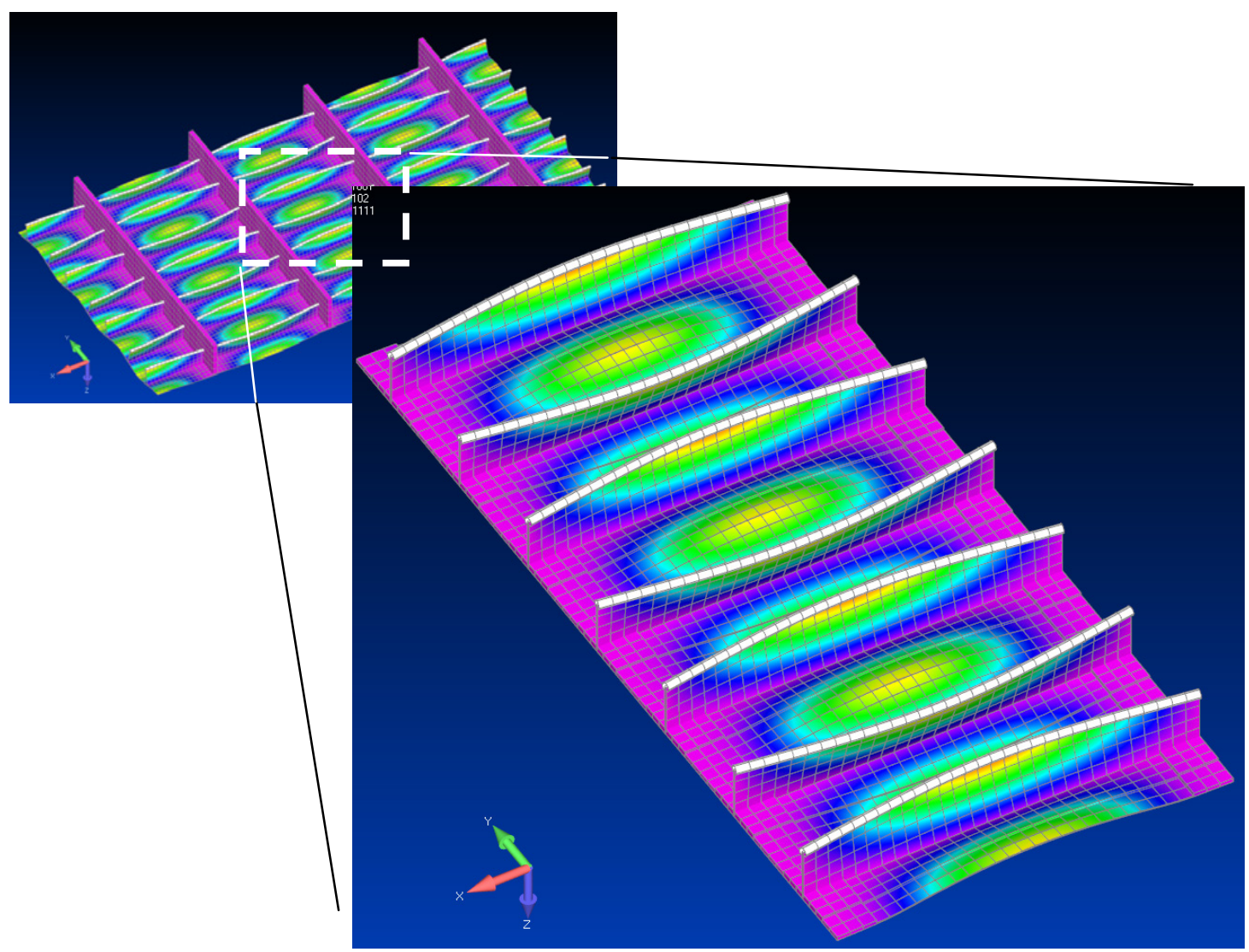

Figure 18.-Illustration of torsional buckling of the stringers in a PRSEUS panel.

A closed-form method was developed by Argyris (Ref. 18) for metallic, single skin-stiffened panels. This method has been implemented and generalized in HyperSizer. Details of the method are not presented here but can be found in the HyperSizer documentation. Enhancements to the method include:

- General cross-sections (the original method only considered Z-type stringers)

- Bonded and riveted panels

- Composite materials

- Stiffening rods (rather than a free flange)

One feature of the PRSEUS concept that is not directly addressed by HyperSizer is the presence of stitching. Our understanding is that the purpose of the PRSEUS stitching is to increase the damage tolerance of the composite materials and to arrest cracks that might otherwise grow catastrophically in a more traditional composite. Our assumption is that stitching does not, however, affect the analysis methodology. Rather the effects of stitching are accounted for both in the composite modulus of elasticity and failure allowable material properties that are inputs to the HyperSizer analysis process. Therefore for purposes of calculating stability and failure methods in HyperSizer, no adjustment was made to account for stitching.

More importantly, stitching does affect the philosophy of assigning material allowables. With traditional composite design, the allowable strains can be "knocked down" more than 50 percent to account for Barely VIsible Damage (BVID) or Compression After Impact (CAI). A pristine coupon test with an average failure strain around $9000 \mu \mathrm{in}$./in. might be used in a design where the design-to strain allowable is below $4000 \mu \mathrm{in}$./in. to account for strength reduction due to BVID. In a stitched design, however, this practice might be overly conservative and higher design allowables might be used. 
Regardless, this is more of a design philosophy issue rather than an analysis or sizing issue addressed directly in HyperSizer.

\subsection{Results and Discussion}

\subsection{Reinforced Core Sandwich (RCS) Panels}

\subsubsection{Verification/Validation Results}

To verify the validity of the local buckling solution under shear loading, Equation (8), without the foundational support (i.e., $K=0$ ), comparison is made to Saydel's (Ref. 19) solution for $[\theta /-\theta / \theta /-\theta]$ antisymmetric balanced angle-ply laminates. This class of laminates exhibits no normal-shear coupling $\left(A_{16}=A_{26}=D_{16}=D_{26}=0\right)$, but does have nonzero coupling stiffness terms, which are ignored by the Saydel (Ref. 19) solution and that presented above, Equation (8). The properties for the ply considered are given in Table 4. In Figure 19 the predicted critical shear buckling load is plotted versus the lamination angle for Saydel's exact solution, finite element analysis (FEA) performed using Abaqus linear shell elements, and the present approximate solution, Equation (8). The FEA solution does include the effects of the coupling stiffness terms of the laminates. As Figure 19 shows, the present solution gives a good approximation of the exact and FEA solutions (without foundational support) with a very simple and efficient equation. The maximum difference of the present solution from the FEA is 6.5 percent.

Tests were also conducted to validate the local buckling solution for webs in RCS panels using specimens extracted from an RCS panel containing a single web like that shown in Figure 20. The predicted buckling loads from Equation (8), where the effective stiffness approach was used for $K$ (Eq. (12)) are compared with experimental results in Table 5. Clearly, the approximate solution matches quite well with the experimental data.
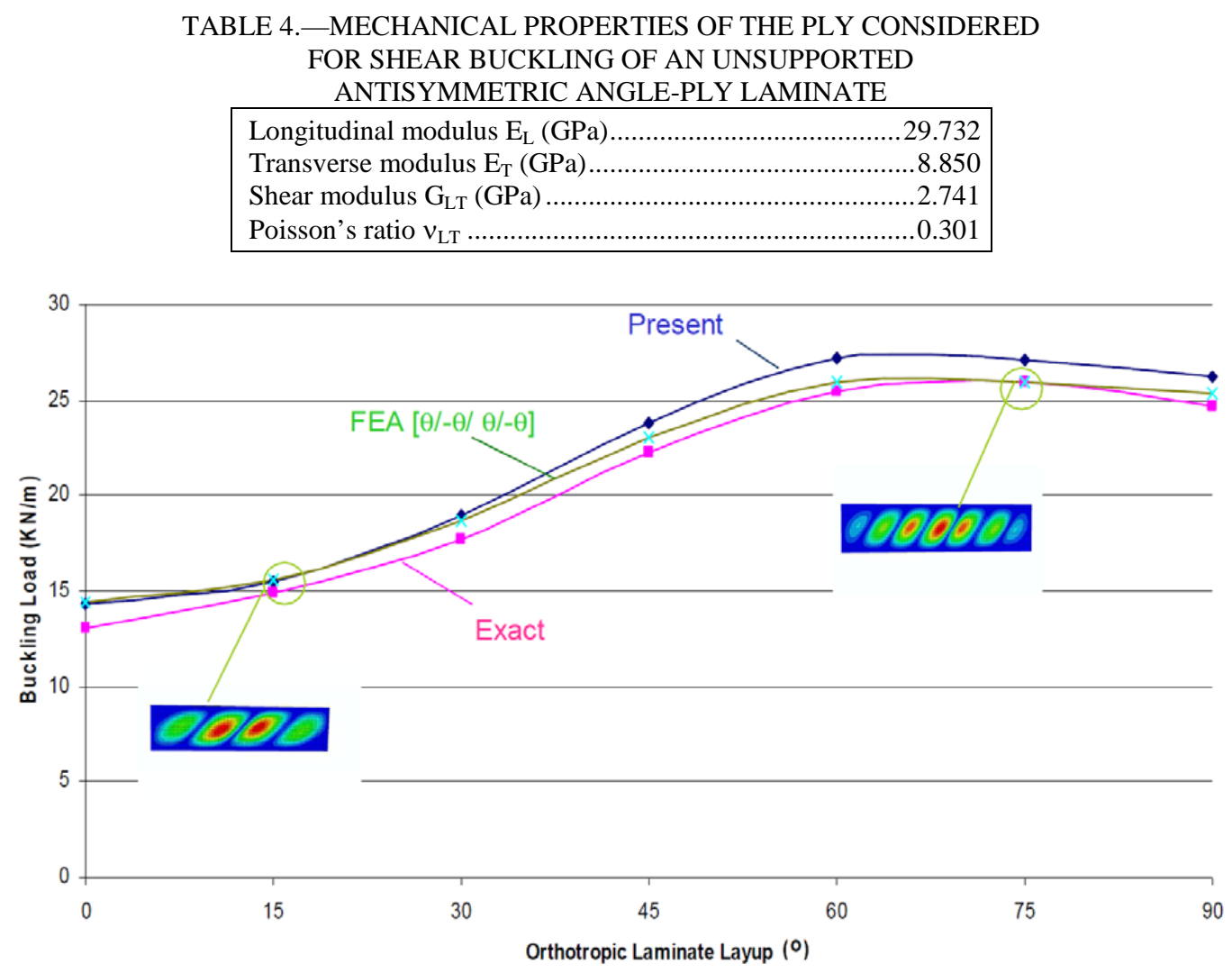

Figure 19.-Comparison of buckling load prediction for an unsupported antisymmetric angle-ply laminate by the present solution, the exact solution (Ref. 19), and FEA. 
TABLE 7.-COMPARISON OF OBJECT LOADS BETWEEN HyperSizer AND FEA

\begin{tabular}{|l|c|c|c|c|}
\cline { 2 - 4 } \multicolumn{1}{c|}{} & \multicolumn{2}{c|}{$\begin{array}{c}c \\
\text { Nx } \\
\text { (lb/in.) }\end{array}$} & \multicolumn{2}{c|}{ (lb/in.) } \\
\cline { 2 - 5 } \multicolumn{1}{c|}{} & HyperSizer & FEA & HyperSizer & FEA \\
\hline Top face combo & -2219 & -2219 & 248 & 244 \\
\hline Web & -166 & -166 & -12 & -13 \\
\hline Bottom face combo & -2219 & -2220 & 248 & 244 \\
\hline
\end{tabular}

\begin{tabular}{|c|c|c|c|c|c|c|}
\hline$t_{1}$ & $t_{2}$ & $t_{3}$ & $t_{4}$ & $t_{5}$ & $S_{x}$ & $H_{\text {total }}$ \\
\hline 0.05 & $t_{3} / 2$ & 0.0166 & $t_{3} / 2$ & 0.05 & 3.5 & 2 \\
\hline
\end{tabular}

(all dimensions in inches)

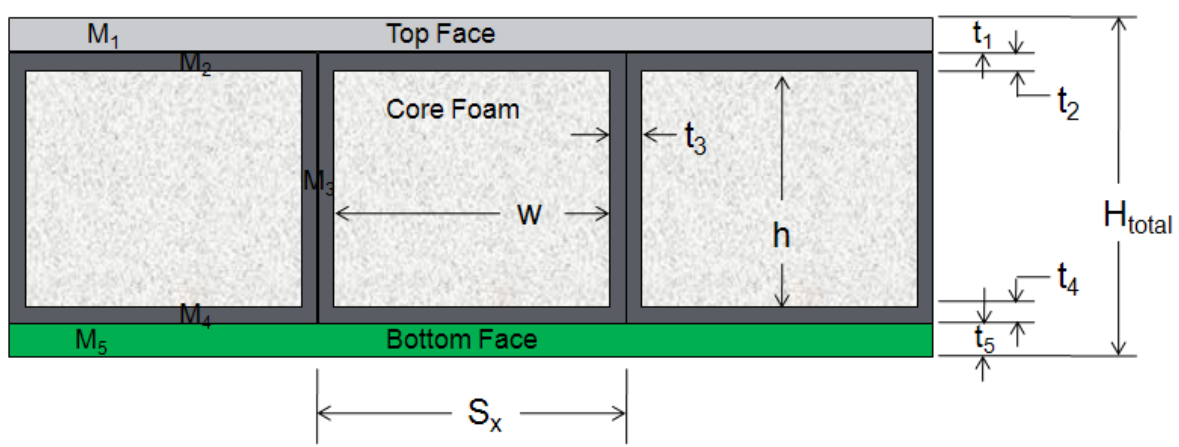

Figure 21.-Dimension of the RCS panel modeled using the new HyperSizer methods and FEA.
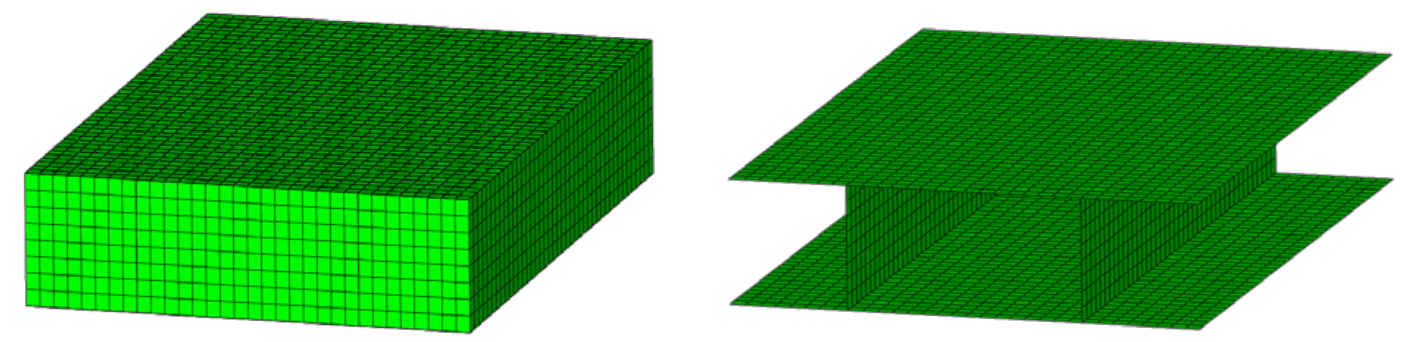

Figure 22.-Converged mesh used for RCS panel shown both with and without the foam elements.

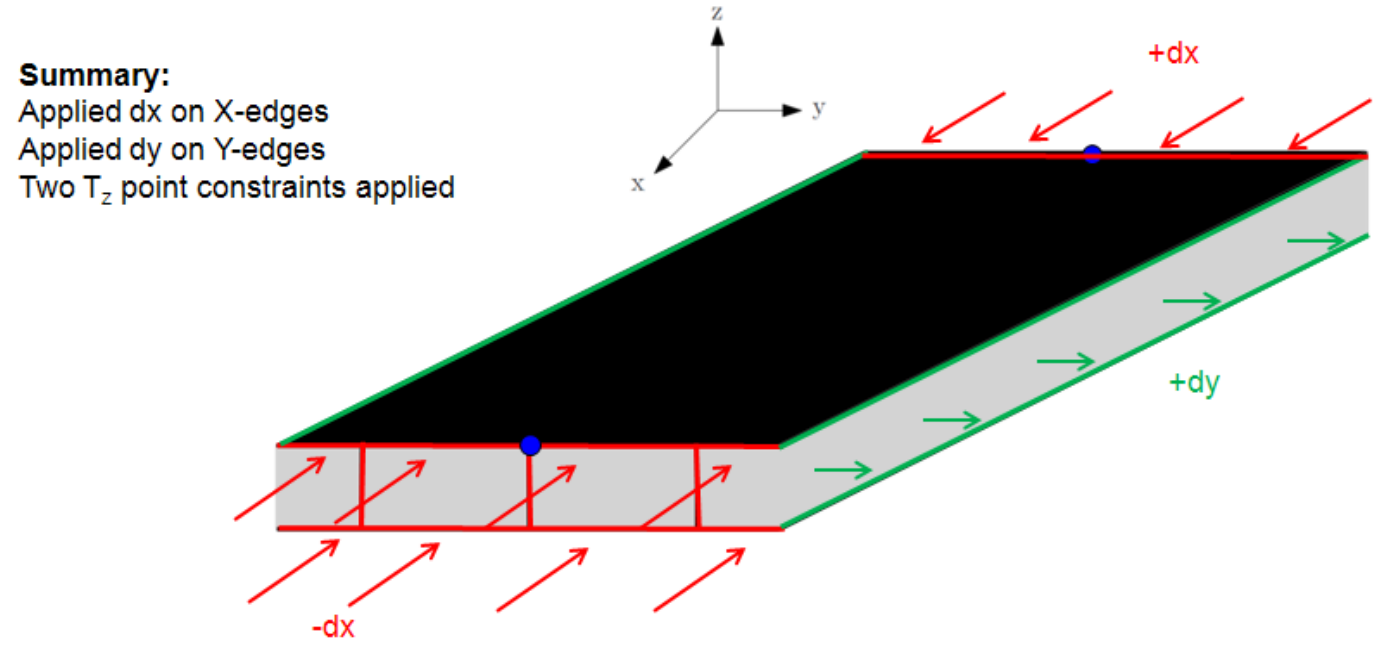

Figure 23.-Static boundary conditions imposed to simulate biaxial loading on RCS panel. 

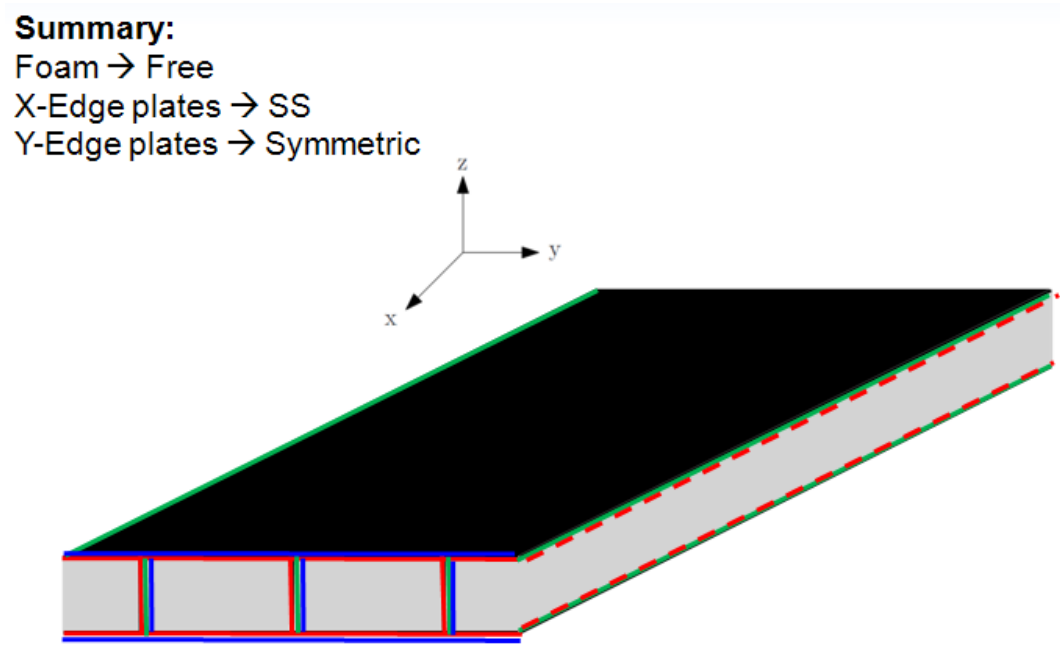

Figure 24.-Buckling boundary conditions imposed to simulate biaxial loading on RCS panel.

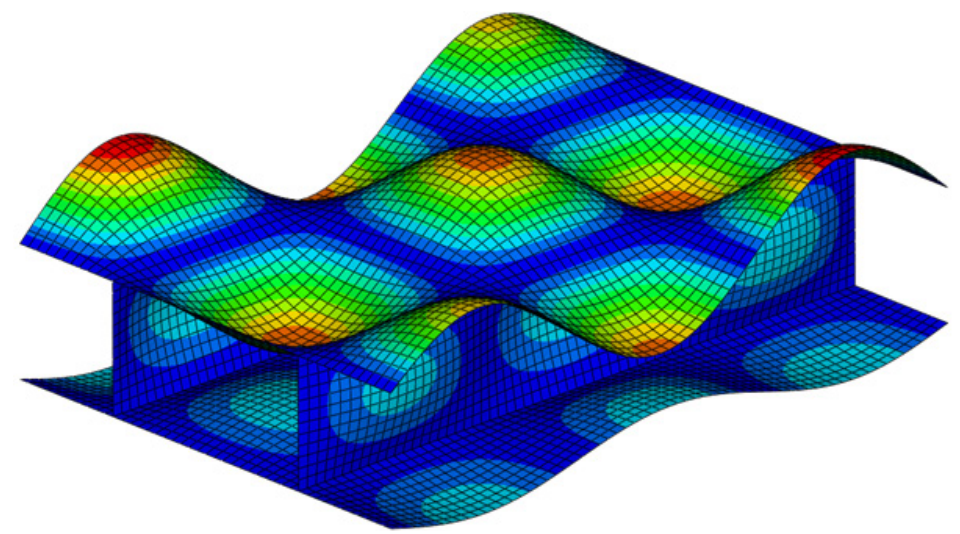

Figure 25.-FEA buckled mode shape for an RCS panel with no foam (i.e., a blade stiffened sandwich panel).

For eigenvalue buckling analysis, the same boundary conditions depicted in Figure 23 were imposed as the perturbation, and the buckling boundary conditions involved leaving the foam boundaries free, treating the y-boundaries of the shells as symmetric, and imposing simple support on the x-boundaries of shells, see Figure 24. Performing the buckling analysis first on a panel with the foam removed, a minimum eigenvalue of 0.234 resulted, with the mode shape shown in Figure 25. In this case, the presented solution predicts an eigenvalue (buckling load/applied load) of 0.24 for the web and 0.19 for the web. Clearly, from Figure 25, the FE solution indicates that the buckling of the web and facesheet are coupled. Considering the presented solution eigenvalue of the web, the presented solution is conservative with respect to FEA by 18 percent.

When the foam is included in the FEA buckling analysis, the minimum eigenvalue rises to 1.12, an increase of 4.8 times. The mode shape for this case is shown in Figure 26. The presented solution predicts a minimum eigenvalue (in the facesheet) of 0.49 using the effective stiffness $K$ approach, and 1.00 using the Hetenyi $K$ approach. These values are 56 and 9 percent conservative with respect to the FEA results, respectively. Varying the Young's modulus of the foam (while maintaining the Poisson ratio), Figure 27 compares the effective stiffness $K$ and the Hetenyi $K$ predictions for the presented method with the FEA solutions for facesheet buckling of the RCS panel. As the foam material becomes stiffer, the effective 


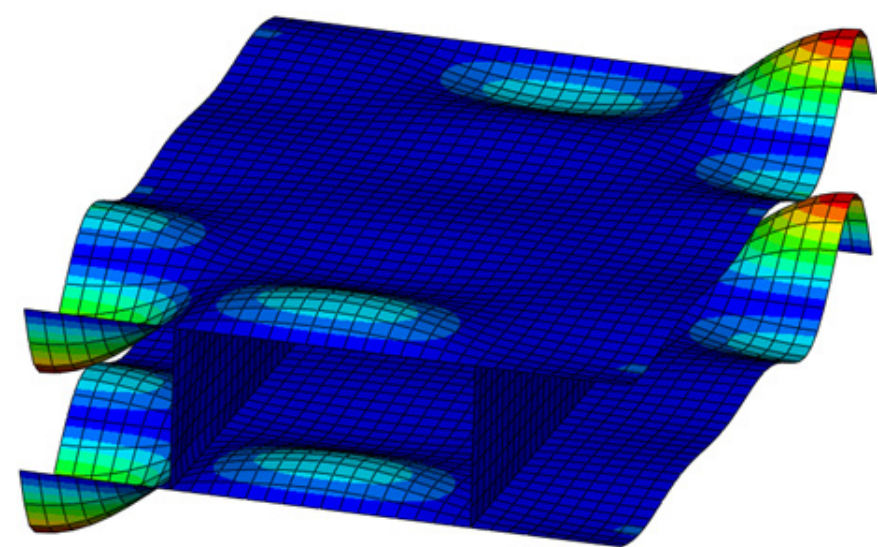

Figure 26.-FEA buckled mode shape for an RCS panel (including foam).

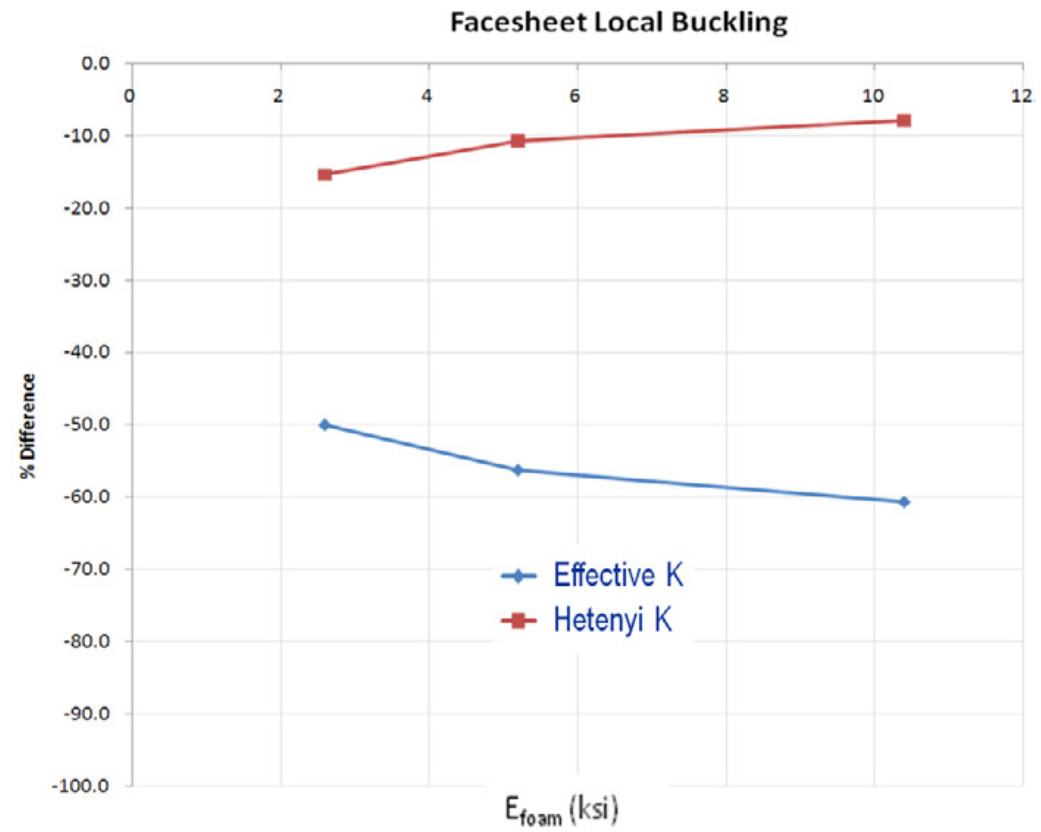

Figure 27.-Difference between the presented solution for facesheet buckling and the FEA predictions as a function of the foam stiffness for the effective stiffness and Hetenyi approaches for determining $K$.

stiffness approach becomes more conservative, while the Hetenyi approach becomes less conservative. It appears that to obtain the best agreement with FEA, while still remaining somewhat conservative, the Hetenyi approach is preferable, whereas, the effective stiffness approach is extremely conservative.

\subsubsection{Sizing Results}

To show the effects of the new sizing capability for RCS within HyperSizer, comparison has been made to two lower fidelity approaches used previously within HyperSizer to size RCS panels. The first approach treats the RCS panel like a honeycomb sandwich panel in HyperSizer, where the core is selected from a number of candidate materials whose properties are provided by the vendor. The facesheet is then sized independently, but, in the case of RCS, the web thickness, spacing, layup, and material cannot be sized/selected. Rather, effective, or smeared, properties are used for the core. In addition, this approach neglects any in-plane contribution of the core webs. For this approach, the core materials given in Table 8 were used as the candidate effective core materials. 
TABLE 8.-CANDIDATE CORE MATERIAL PROPERTIES USED IN

THE EFFECTIVE CORE APPROACH TO SIZING RCS

\begin{tabular}{|l|c|c|c|c|c|c|c|c|c|}
\cline { 2 - 10 } \multicolumn{1}{c|}{} & $\begin{array}{c}\text { Density } \\
(\mathrm{pcf})\end{array}$ & $\begin{array}{c}\text { Et } \\
(\mathrm{ksi})\end{array}$ & $\begin{array}{c}\text { Ec } \\
(\mathrm{ksi})\end{array}$ & $\begin{array}{c}\text { Gw } \\
(\mathrm{ksi})\end{array}$ & $\begin{array}{c}\text { Gl } \\
(\mathrm{ksi})\end{array}$ & $\begin{array}{c}\text { Ftu } \\
(\mathrm{psi})\end{array}$ & $\begin{array}{c}\text { Fsuw } \\
(\mathrm{psi})\end{array}$ & $\begin{array}{r}\text { Fsul } \\
(\mathrm{psi})\end{array}$ & $\begin{array}{c}\text { Fcus } \\
(\mathrm{psi})\end{array}$ \\
\hline WebCore A & 4.1 & 26.1 & 26.1 & 1.88 & 44.7 & 272 & 89 & 234 & 352 \\
WebCore Light Bi & 7.5 & 68.0 & 68.0 & 9 & 35 & 1641 & 145 & 473 & 1641 \\
\hline TYCOR 126-C06 & 11.7 & 314 & 314 & 147 & 212 & 710 & 764 & 538 & 2000 \\
TYCOR 94-C1 & 3.9 & 23.1 & 23.1 & 1.90 & 37.5 & 305 & 60 & 231 & 355 \\
\hline
\end{tabular}

The second lower fidelity method for sizing RCS panels in HyperSizer involves treating the panel as a blade-stiffened sandwich panel within the code. The panel is then sized without foam, and the mass of the foam is added to the panel mass as a post-processing step. To account for the local buckling support of the foam, the loads in the facesheet and webs were permitted to be 300 percent of the buckling load calculated by HyperSizer for the unsupported local buckling case. This 300 percent factor was determined via trial and error to give reasonable results versus experimental observations, but it is clearly an ad hoc method. This blade-stiffened sandwich panel approach does allow the sizing of the web thickness and spacing, along with the material and layup selection, but the wrap layer is not accounted for in the facesheet combo. Note that the wrap layer could be manually added to the facesheet, but it would not be active in the sizing process.

To compare these two lower fidelity sizing methods with the new method presented, a panel level sizing was performed with loading similar to the acreage of NASA's Ares V interstage. This is a $33 \mathrm{ft}$. diameter cylinder subjected primarily to axial compression, but with some hoop and in-plane shear load due to bending of the rocket stack during flight. The actual loads employed cannot be disclosed, but the axial compressive load is in the mid-thousands of $\mathrm{lb} / \mathrm{in}$, and the remaining loads employed for strength and buckling sizing are given with respect to the axial load $\mathrm{N}_{\mathrm{x}}$ in Table 9. A 1.4 ultimate factor, a 1.0 limit factor, and a 0.65 panel buckling knockdown were employed in the sizing. Effective laminates constructed from IM7/8552 open hole compression ply properties were used for the facesheets and webs, with a maximum of 75 percent $0^{\circ}$ plies in the facesheets and 45 percent $0^{\circ}$ plies in the webs. Four Rohacell (Ref. 20) foam material candidates, ranging from 2 to $6.9 \mathrm{lb} / \mathrm{ft}^{3}$ density, were considered. The $\mathrm{x}$-direction buckling length of each sized panel was varied from 15 in. to 120 in. to simulate the effects of ring frame spacing on the panel areal weight. In an axially-compressed cylinder, the main function of the ring frames are to limit the buckling half-wave length to the distance between the rings. This reduced buckling length then allows the panels to be thinner and thus lighter.

TABLE 9.-NORMALIZED PANEL LEVEL LOADING IMPOSED ON THE REPRESENTATIVE ARES V INTERSTAGE ACREAGE PANEL

\begin{tabular}{|l|c|c|c|}
\cline { 2 - 4 } \multicolumn{1}{c|}{} & $\mathrm{N}_{\mathrm{x}}$ & $\mathrm{N}_{\mathrm{y}}$ & $\mathrm{N}_{\mathrm{xy}}$ \\
\hline Strength & $-\mathrm{N}_{\mathrm{x}}$ & $-0.099 \mathrm{~N}_{\mathrm{x}}$ & $-0.052 \mathrm{~N}_{\mathrm{x}}$ \\
\hline Buckling & $-0.47 \mathrm{~N}_{\mathrm{x}}$ & $-0.098 \mathrm{~N}_{\mathrm{x}}$ & $-0.026 \mathrm{~N}_{\mathrm{x}}$ \\
\hline
\end{tabular}

Results for the Ares V interstage panel sizing are shown in Figure 28. The panel areal weights (weight per unit area) are plotted versus buckling length for the effective, or smeared, property approach, the blade-stiffened sandwich approach and for the newly implemented approach using the effective stiffness $K$ and the Hetenyi $K$. It is noted that in all cases, the lightest effective core and foam material candidates were chosen. The areal weight increases nonlinearly for all approaches because the panel height increases due to the increasing buckling span length, but the height can increase in a weight efficient manner by increasing the low density core. The results show that the new HyperSizer method using the Hetenyi approach yields significantly lighter designs for the RCS panels compared to the other methods. The other methods are fairly close in areal weight, except at the higher buckling lengths, where 
the new HyperSizer approach with the effective stiffness $K$ diverges from the effective property and blade-stiffened approaches, which are the heaviest. Table 10 provides details of the sized panels for buckling lengths of 30-, 75-, and 120-in. As the buckling length increases, the effective core design tends towards a large panel height as this approach does not consider buckling of the webs, which becomes more problematic as the webs become tall. The blade stiffened sandwich panel design tends toward thick webs, indicating that, while the 300 percent local buckling factor may be reasonable for facesheet buckling, it is too conservative for the webs. The new HyperSizer concept using the effective stiffness $K$ tends toward thicker facesheets that the other approaches, a further indication that this approach may be too conservative for facesheet buckling.

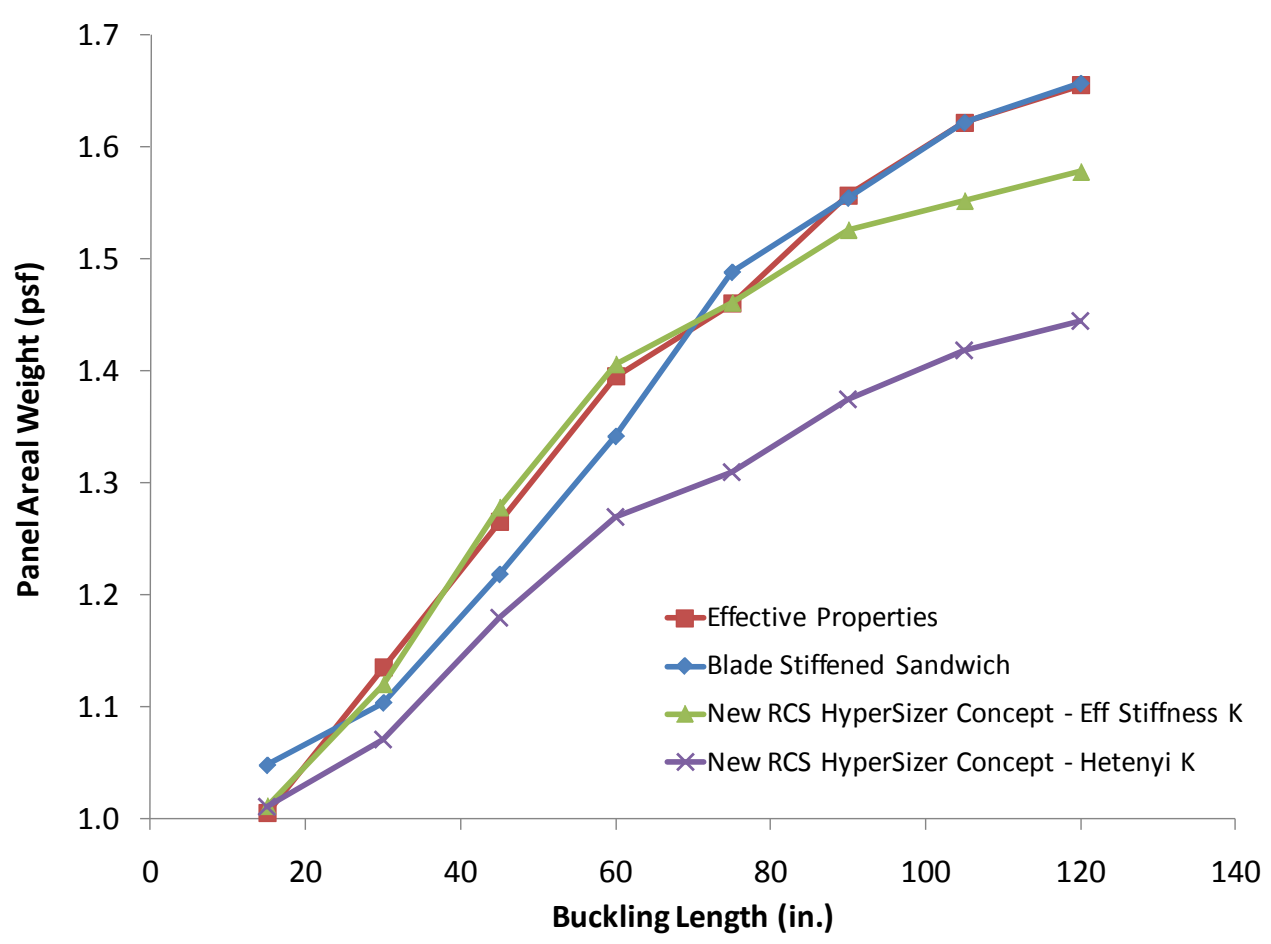

Figure 28.-Panel areal weight versus ring frame spacing for the Ares $\mathrm{V}$ interstage acreage panel sized using different methods.

TABLE 10.-PANEL SIZING RESULTS FOR ARES V INTERSTAGE ACREAGE PANEL

\begin{tabular}{|l|c|c|c|c|c|c|c|c|c|c|c|c|}
\hline \multirow{2}{*}{\multicolumn{1}{|c}{ Buck L }} & \multicolumn{4}{|c|}{30 in. } & \multicolumn{4}{c|}{75 in. } & \multicolumn{4}{c|}{120 in. } \\
\cline { 2 - 13 } & $\begin{array}{c}\text { Eff. } \\
\text { core }\end{array}$ & Blade & $\begin{array}{c}\text { New } \\
\text { eff. K }\end{array}$ & $\begin{array}{c}\text { New } \\
\text { Het. K }\end{array}$ & $\begin{array}{c}\text { Eff. } \\
\text { core }\end{array}$ & Blade & $\begin{array}{c}\text { New } \\
\text { eff. K }\end{array}$ & $\begin{array}{c}\text { Conc. } \\
\text { Het. K }\end{array}$ & $\begin{array}{c}\text { Eff. } \\
\text { core }\end{array}$ & $\begin{array}{c}\text { Blade } \\
\text { New } \\
\text { eff. K }\end{array}$ & $\begin{array}{c}\text { Conc. } \\
\text { Het. K }\end{array}$ \\
\hline Areal weight (lb/ft ${ }^{2}$ ) & 1.14 & 1.10 & 1.12 & 1.07 & 1.46 & 1.49 & 1.46 & 1.31 & 1.66 & 1.66 & 1.58 & 1.45 \\
Panel height (in.) & 1.0 & 1.1 & 1.0 & 1.1 & 2.0 & 2.0 & 1.7 & 2.0 & 2.8 & 2.4 & 1.9 & 2.3 \\
FS thickness (plies) & 9 & 8 & 9 & 8 & 9 & 9 & 11 & 8 & 9 & 10 & 12 & 9 \\
Web thickness (plies) & - & 4 & 4 & 4 & - & 6 & 4 & 4 & - & 6 & 4 & 4 \\
Web spacing (in.) & - & 1.1 & 1.2 & 1.2 & - & 1.7 & 1.7 & 1.4 & - & 2.0 & 2.0 & 1.7 \\
\hline
\end{tabular}




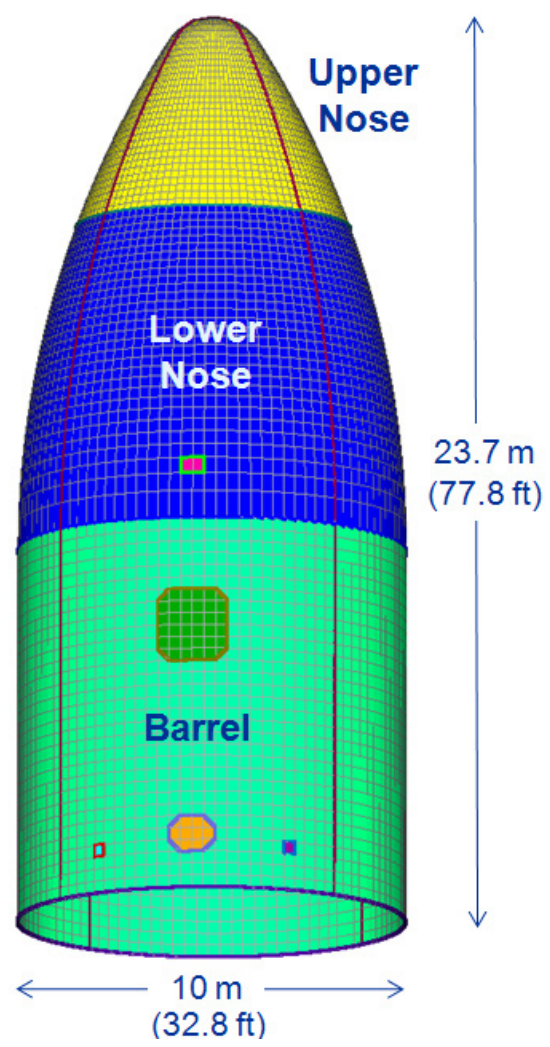

Figure 29._NASA's Ares V payload shroud FE model.

To compare the four approaches for sizing RCS panels for a full structure, the design of NASA's Ares V payload shroud was considered. This large structure, shown in Figure 29, protects the payload during launch and ascent. The panels of the structure were divided into three components, the upper nose, lower nose, and barrel, each separated by a ring frame. Four longitudinal separation rails are present in the structure, but these are not sized to carry load as their main purpose is to enable separation of the four petals to reveal the payload. There are also five cutouts, each with a frame. In this case, unlike the interstage acreage panel sizing described previously, the loads vary over the structure and each panel component is sized to its design-to loads. The structure was subjected to six load cases: max. G plus thermal, max Q, and four max. Q $\alpha$ cases clocked at $90^{\circ}$ around the circumference of the shroud. Because the payload shroud is at the top of the vehicle, the loads are significantly lower (5 to 20 percent) than those of the interstage. As in the interstage, a 1.4 ultimate factor, a 1.0 limit factor, and a 0.65 buckling knockdown were employed. Unlike the interstage, both the facesheet and webs were sized using [0/ $\pm 45 / 90]$ IM7/977-3 effective laminate material properties. Again, the lightest effective core and lightest foam material candidates were always selected.

Figure 30 provides the average areal weight comparison for the four approaches for the Ares $\mathrm{V}$ payload shroud, while Table 11 to Table 13 provide the sizing details for the three panel components. Again, it is clear that the new HyperSizer concept, with the Hetenyi foundational stiffness, provides a significantly lighter-weight design than the other methods. Comparing this design to that using the effective foundational stiffness approach, the web spacing is much larger and the facesheet much thinner using the Hetenyi approach. This is expected as the effective stiffness approach is far more conservative for facesheet buckling. With the thicker facesheets and lower web spacing, the effective stiffness $K$ approach panel height is smaller, but this is clearly a much less weight efficient design. The 
blade-stiffened panel approach design is comparable in average areal weight to the new effective stiffness $K$ approach, however, the panel height is higher, the facesheets are thinner, and the web spacing is lower.

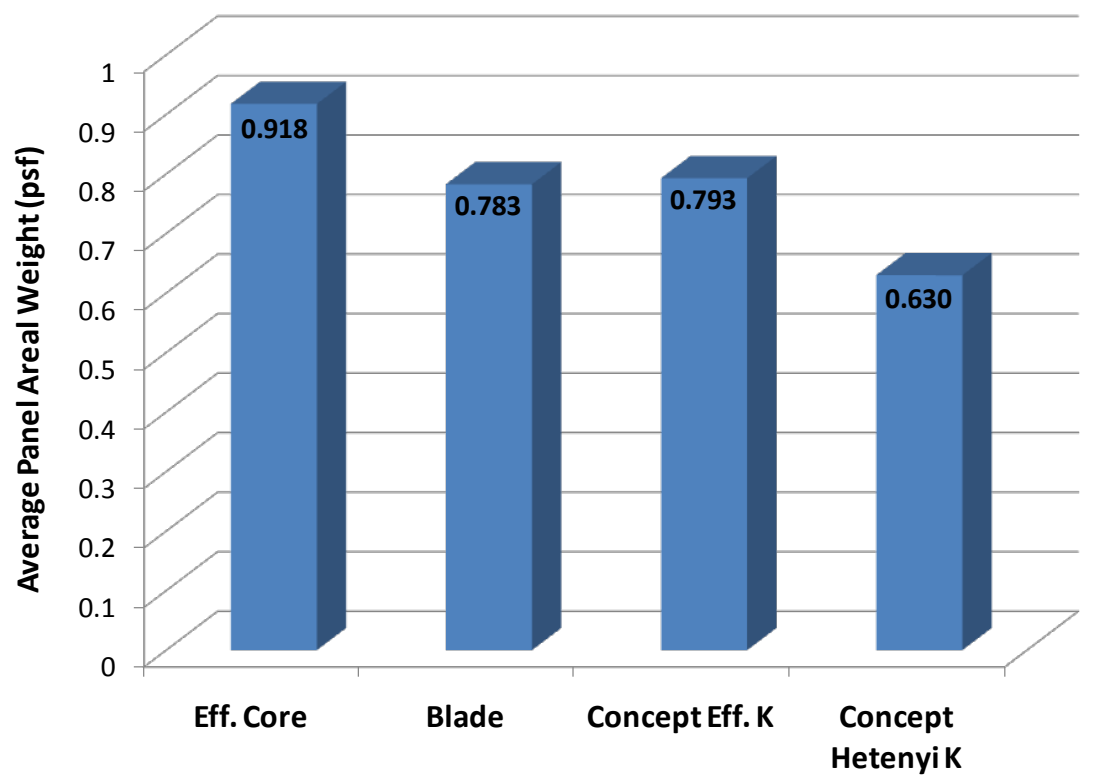

Figure 30.-Average panel areal weight results for the Ares $\mathrm{V}$ payload shroud sized using different methods.

TABLE 11.-RCS PANEL DESIGN DETAILS FOR THE ARES V PAYLOAD SHROUD UPPER NOSE

\begin{tabular}{|l|c|c|c|c|}
\hline \multicolumn{1}{|c|}{ Upper nose } & Eff. core & Blade & New eff. K & New Het. K \\
\hline Areal weight (psf) & 0.88 & 0.87 & 0.81 & 0.70 \\
Height (in.) & 1.67 & 1.50 & 1.25 & 1.75 \\
Facesheet (plies) & 4 & 4 & 7 & 4 \\
Web (plies) & - & 4 & 4 & 4 \\
Web spacing (in.) & - & 1.0 & 3.0 & 6.0 \\
\hline
\end{tabular}

TABLE 12.--RCS PANEL DESIGN DETAILS FOR THE ARES V PAYLOAD SHROUD LOWER NOSE

\begin{tabular}{|l|c|c|c|c|}
\hline \multicolumn{1}{|c|}{ Lower nose } & Eff. core & Blade & New eff. K & New Het. K \\
\hline Areal weight (psf) & 0.88 & 0.74 & 0.77 & 0.60 \\
Height (in.) & 1.67 & 1.0 & 0.75 & 1.25 \\
Facesheet (plies) & 4 & 4 & 7 & 4 \\
Web (plies) & - & 5 & 4 & 4 \\
Web spacing (in.) & - & 1.0 & 4.0 & 6.0 \\
\hline
\end{tabular}

TABLE 13.-RCS PANEL DESIGN DETAILS FOR THE ARES V PAYLOAD SHROUD BARREL

\begin{tabular}{|l|c|c|c|c|}
\hline \multicolumn{1}{|c|}{ Barrel } & Eff. core & Blade & New eff. K & New Het. K \\
\hline Areal weight (psf) & 0.96 & 0.79 & 0.80 & 0.64 \\
Height (in.) & 1.67 & 1.25 & 0.75 & 1.0 \\
Facesheet (plies) & 5 & 4 & 7 & 5 \\
Web (plies) & - & 4 & 4 & 4 \\
Web spacing (in.) & - & 1.0 & 2.0 & 6.0 \\
\hline
\end{tabular}




\subsection{Pultruded Rod Stitched Efficient Unitized Structure (PRSEUS) Panels}

\subsubsection{Verification and Validation Results}

Verification studies for PRSEUS methods were carried out on a PRSEUS panel fabricated and tested by Boeing. The overall panel dimensions of the panel are 80 -in. long by 42 -in. wide with a frame spacing of $20 \mathrm{in}$. and a stringer spacing of 6 in. (7 stringers across the panel width). The as-fabricated panel is shown in Figure 3. The lamina used to make up the facesheet, stringer, and flange laminates consisted of "stacks" of AS4 fibers infused with epoxy resin. Each stack was 0.052 in. thick and consisted of 7 plies as shown in Table 14.

TABLE 14.-FACESHEET, STRINGER,
AND FLANGE LAMINATE LAYUPS FOR
THE SIMULATED PRSEUS PANEL
\begin{tabular}{|c|c|c|}
\hline Ply & Thickness & Angle \\
\hline 7 & 0.0056 & +45 \\
6 & 0.0056 & -45 \\
5 & 0.0117 & 0 \\
4 & 0.0056 & 90 \\
3 & 0.0117 & 0 \\
2 & 0.0056 & -45 \\
1 & 0.0056 & +45 \\
\hline
\end{tabular}

The stringer dimensions are shown in Figure 31. The frame dimensions are shown in Figure 32. Two different panels were fabricated with identical stringers and frames. The first panel had a two-stack skin with a thickness of $0.104 \mathrm{in}$. and the second panel had a one-stack skin with a thickness of $0.052 \mathrm{in}$. The HyperSizer verifications described below used the second configuration with 0.052 in. thick facesheets. Further fabrication details along with material stiffness and failure properties can be found in References 4 and 21.
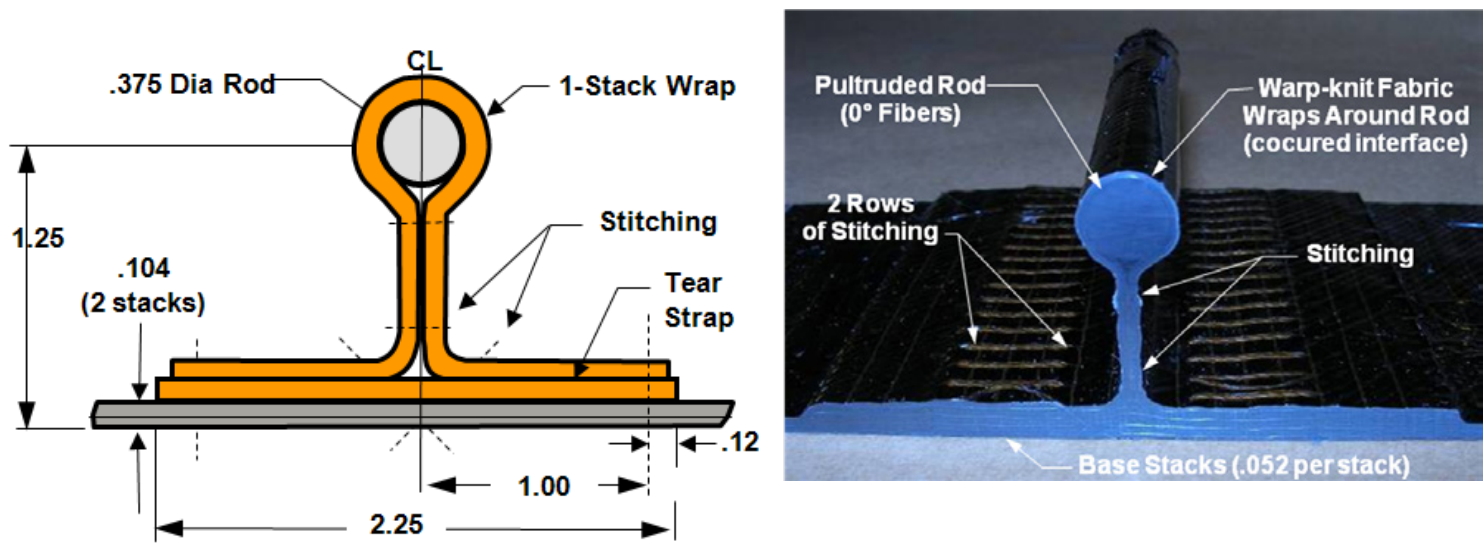

Figure 31.-Stringer dimensions for the simulates PRSEUS panel. 


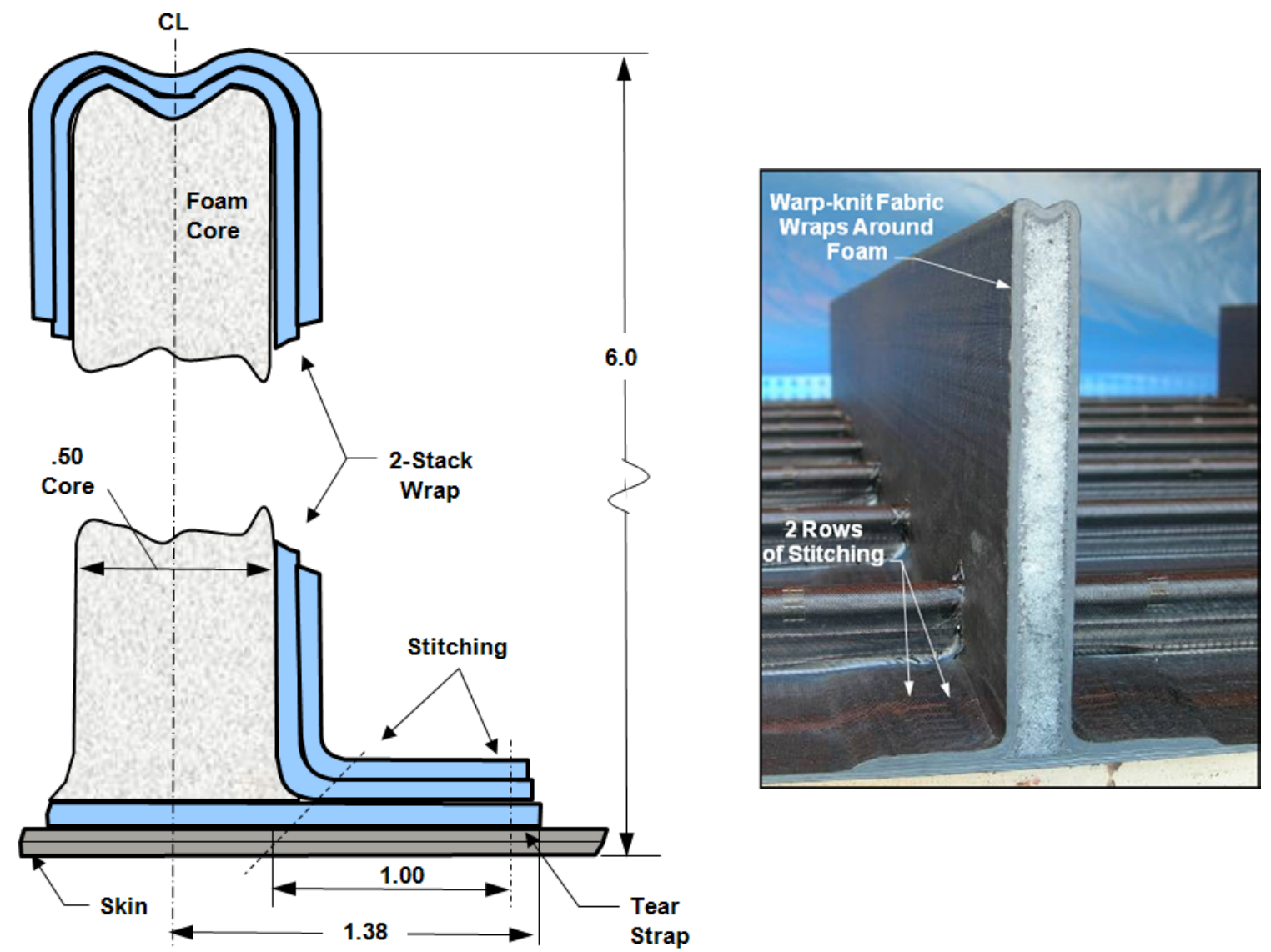

Figure 32.-Frame dimensions for the simulated PRSEUS panel.

\subsubsection{FEA Verification of Thermoelastic Formulation}

The ABD matrix verification is performed by constructing a discrete FE model of a PRSEUS panel using plate elements with PCOMP composite properties and beam elements representing the stiffener rod. Four separate load conditions, as shown in Figure 33, were applied to obtain load-strain and momentcurvature response to back-out panel level ABD matrices.

After applying these four loading conditions, the strains, curvatures and resultant loads were all extracted from the FEA results and used to calculate ABD terms. These were then compared to HyperSizer results of the same panel. We should emphasize that although the panel FE models were generated using HyperSizer, there are no HyperSizer specific constructs in the FE model. In other words, the model uses actual ply stiffness properties and PCOMPs to represent all of the laminates. The panel strain response to the four load cases are listed in Table 15 for HyperSizer and FEA.

The loads and strains can be used to back-out panel ABD terms by expanding the terms of the ABD matrix,

$$
\begin{aligned}
& N_{x}=A_{11} \varepsilon_{x}+A_{12} \varepsilon_{y}+A_{13} \kappa_{x y}+B_{11} \kappa_{x}+B_{12} \kappa_{y}+B_{13} \kappa_{x y} \\
& N_{y}=A_{21} \varepsilon_{x}+A_{22} \varepsilon_{y}+A_{23} \kappa_{x y}+B_{21} \kappa_{x}+B_{22} \kappa_{y}+B_{23} \kappa_{x y}
\end{aligned}
$$

For Case 1, all strains and curvatures are zero except for $\varepsilon_{\mathrm{x}}$, therefore the equations are reduced to:

$$
\begin{aligned}
& N_{x}=A_{11} \varepsilon_{x} \Rightarrow A_{11}=N_{x} / \varepsilon_{x} \\
& N_{y}=A_{21} \varepsilon_{x} \Rightarrow A_{21}=A_{12}=N_{y} / \varepsilon_{x}
\end{aligned}
$$


The other ABD terms can be backed out from the remaining load cases as follows. The comparisons shown in Table 16 indicate a good match between panel level response between HyperSizer and FEA for the PRSEUS panel.

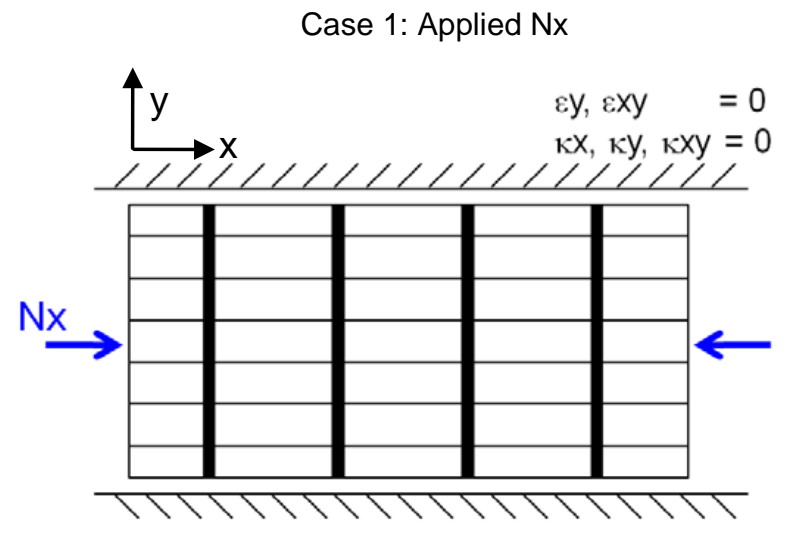

Case 3: Applied Mx

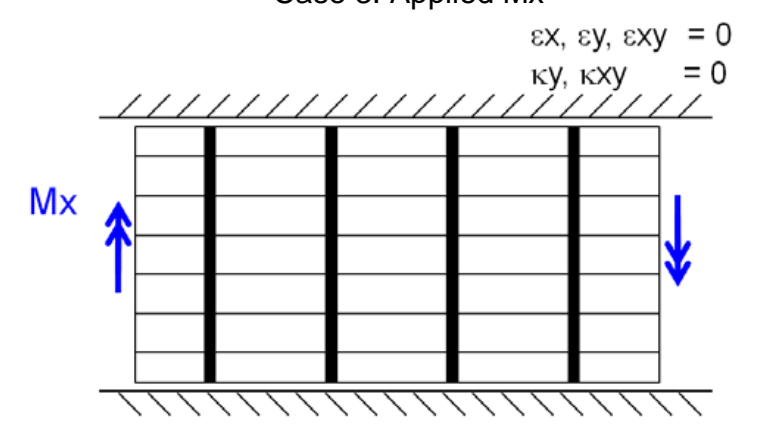

Case 2: Applied Ny

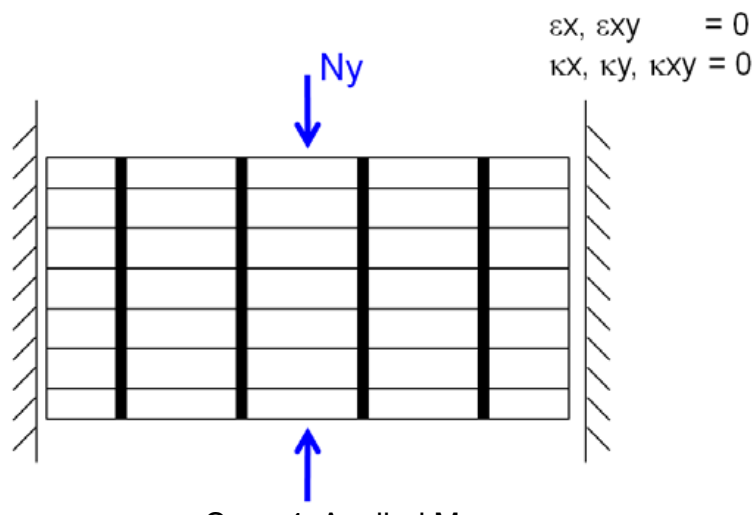

Case 4: Applied My

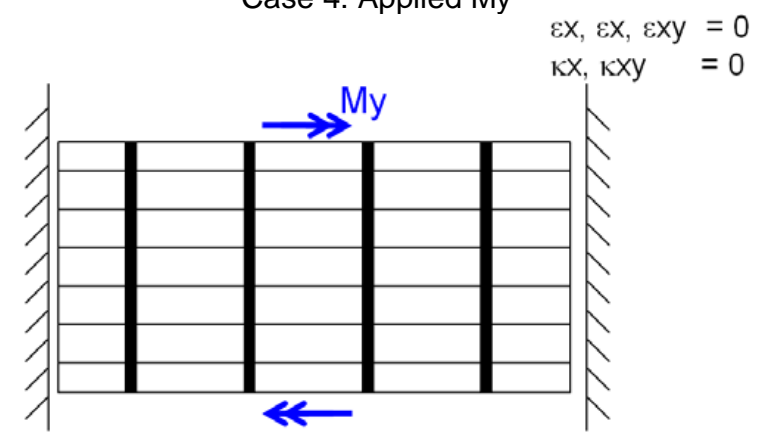

Figure 33.-_Load conditions applied to the simulated PRSEUS panel.

TABLE 15.-COMPARISON OF THE PANEL LEVEL LOADS AND

STRAINS FOR THE SIMULATED PRSEUS PANEL FROM

FEA AND THE NEW HyperSizer CAPABILITY

\begin{tabular}{|c|c|c|c|}
\hline \multicolumn{4}{|c|}{ LC 1-Applied Nx } \\
\hline & FEA & HyperSizer & Difference \\
\hline Nx (lb/in.) & 2,381 & 2,381 & $0.0 \%$ \\
\hline Ny (lb/in.) & 264 & 252 & $4.6 \%$ \\
\hline ex ( $\mu$ in./in.) & 1,596 & 1,642 & $-2.9 \%$ \\
\hline \multicolumn{4}{|c|}{ LC2-Applied Ny } \\
\hline & FEA & HyperSizer & Difference \\
\hline Nx (lb/in.) & 140 & 138 & $1.6 \%$ \\
\hline Ny (lb/in.) & 1,250 & 1,250 & $0.0 \%$ \\
\hline ey ( $\mu$ in./in.) & 842 & 882 & $-4.7 \%$ \\
\hline \multicolumn{4}{|c|}{ LC 3-Applied Mx } \\
\hline & FEA & HyperSizer & Difference \\
\hline Mx (lb-in./in.) & 1,000 & 1,000 & $0.0 \%$ \\
\hline $\mathrm{kx}\left(\times 10^{6} \mathrm{in}^{-1}\right)$ & 1,401 & 1,478 & $-5.5 \%$ \\
\hline \multicolumn{4}{|c|}{ LC2-Applied Ny } \\
\hline & FEA & HyperSizer & Difference \\
\hline My (lb-in./in.) & 1,000 & 1,000 & $0.0 \%$ \\
\hline ky $\left(\times 10^{6} \mathrm{in}^{-1}\right)$ & 135 & 142 & $-5.3 \%$ \\
\hline
\end{tabular}


TABLE 16.-COMPARISON OF THE ABD TERMS FOR THE

SIMULATED PRSEUS PANEL FROM FEA AND

THE NEW HyperSizer CAPABILITY

\begin{tabular}{|c|c|c|c|c|c|}
\hline & LC no. & Formula & FEA & HyperSizer & Difference \\
\hline A11 & 1 & $\mathrm{Nx} / \mathrm{ex}$ & $1,491,942$ & $1,450,016$ & $2.8 \%$ \\
\hline A12 & 1 & Ny/ex & 165,481 & 156,345 & $5.5 \%$ \\
\hline A22 & 2 & Ny/ey & $1,483,805$ & $1,417,502$ & $4.5 \%$ \\
\hline A21 & 2 & Nx/ey & 165,481 & 156,345 & $5.2 \%$ \\
\hline B11 & 1 & $\mathrm{Mx} / \mathrm{ex}$ & 688,367 & 647,876 & $5.9 \%$ \\
\hline B22 & 2 & My/ey & $1,856,107$ & 1,788,691 & $3.6 \%$ \\
\hline D11 & 3 & $\mathrm{Mx} / \mathrm{kx}$ & 713,840 & 676,788 & $5.2 \%$ \\
\hline D22 & 4 & My/ky & $7,416,433$ & $7,044,432$ & $5.0 \%$ \\
\hline
\end{tabular}

In addition to panel level response, loads at the object level are also important for strength, local buckling, and crippling failure analyses. Figure 34 shows a comparison between the FEA extracted local loads and HyperSizer values. A summary of the internal load comparison between FEA and HyperSizer is shown in Table 17.

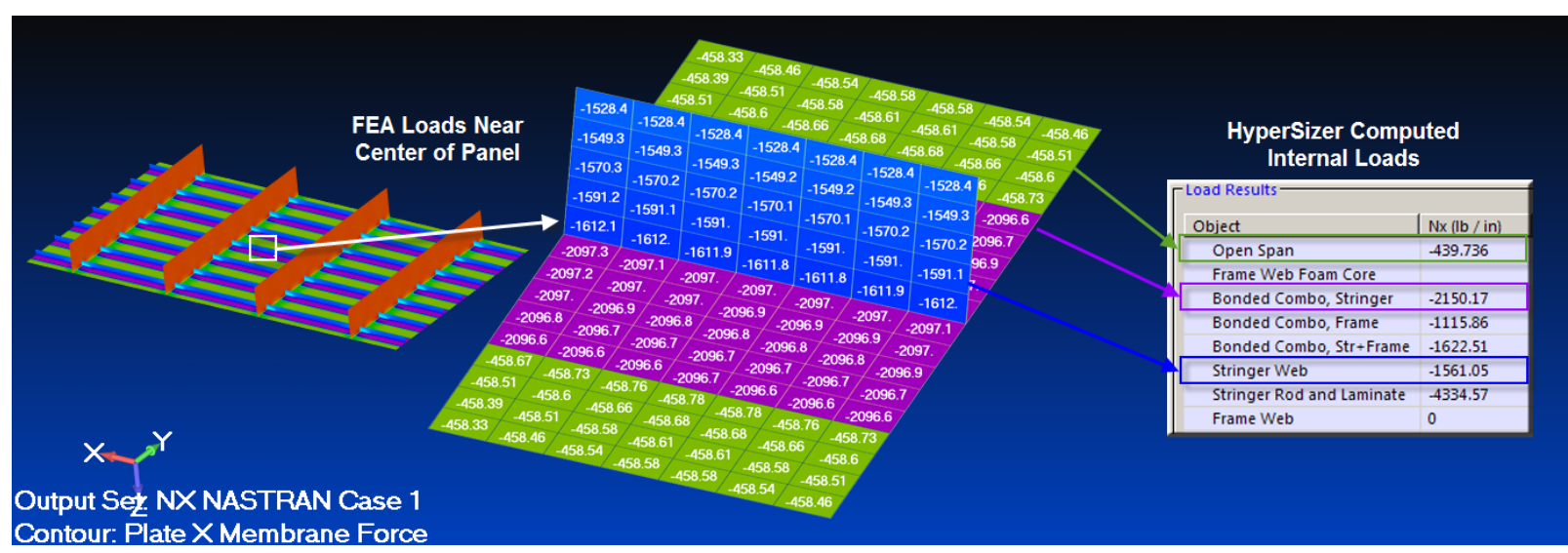

Figure 34.-Comparison of the internal loads in the simulated PRSEUS panel from FEA and the new HyperSizer capability.

TABLE 17.-COMPARISON OF THE INTERNAL LOADS IN THE SIMULATED PRSEUS PANEL FROM FEA AND THE NEW HyperSizer CAPABILITY

\begin{tabular}{|l|c|c|c|}
\hline \multicolumn{1}{|c|}{ Object Nx loads } & FEA & HyperSizer & Percent diff. \\
\hline Open span (lb/in.) & -458 & -440 & 3.9 \\
Bonded combo, stringer & -2097 & -2150 & 2.5 \\
Stringer web & -1570 & -1561 & 0.5 \\
Stiffening rod (lb) & -4267 & -4334 & 1.5 \\
\hline
\end{tabular}




\subsubsection{HyperSizer Prediction of Postbuckling Strength}

In the HyperSizer analysis of this panel, an applied axial load of $2381 \mathrm{lb} / \mathrm{in}$. was applied to the panel. With a panel width of 42 in., this corresponds to a total applied load of 100 kips. The ultimate load of the panel is found from the ultimate margin of safety as $F_{u l t}=F_{\text {applied }}\left(M S_{u l t}-1\right)$. The HyperSizer margins of safety for this panel are shown in Figure 35.

The ultimate margin of safety is panel torsional stability of 1.22 . This yields a failure load of

$$
N_{x}^{u l t}=\left(M S_{u l t}+1\right) N_{x}^{\text {applied }}=(1.22+1) \times 100 \text { kips }=222 \text { kips }
$$

Table 18 summarizes the margins and corresponding loads for various failure modes.

TABLE 18.-MARGINS CALCULATED BY HyperSizer FOR THE SIMULATED PRSEUS PANEL

\begin{tabular}{|l|l|c|}
\hline \multicolumn{1}{|c|}{ Failure mode } & Margin & $\begin{array}{c}\text { Panel load } \\
\text { (kips) }\end{array}$ \\
\hline Torsional buckling & 1.224 & 222 \\
Crippling & 1.874 & 287 \\
Frame span buckling & 2.20 & 320 \\
Material strength (max strain) & 3.6 & 460 \\
Panel buckling (full 80x42 panel) & 4.49 & 549 \\
\hline
\end{tabular}

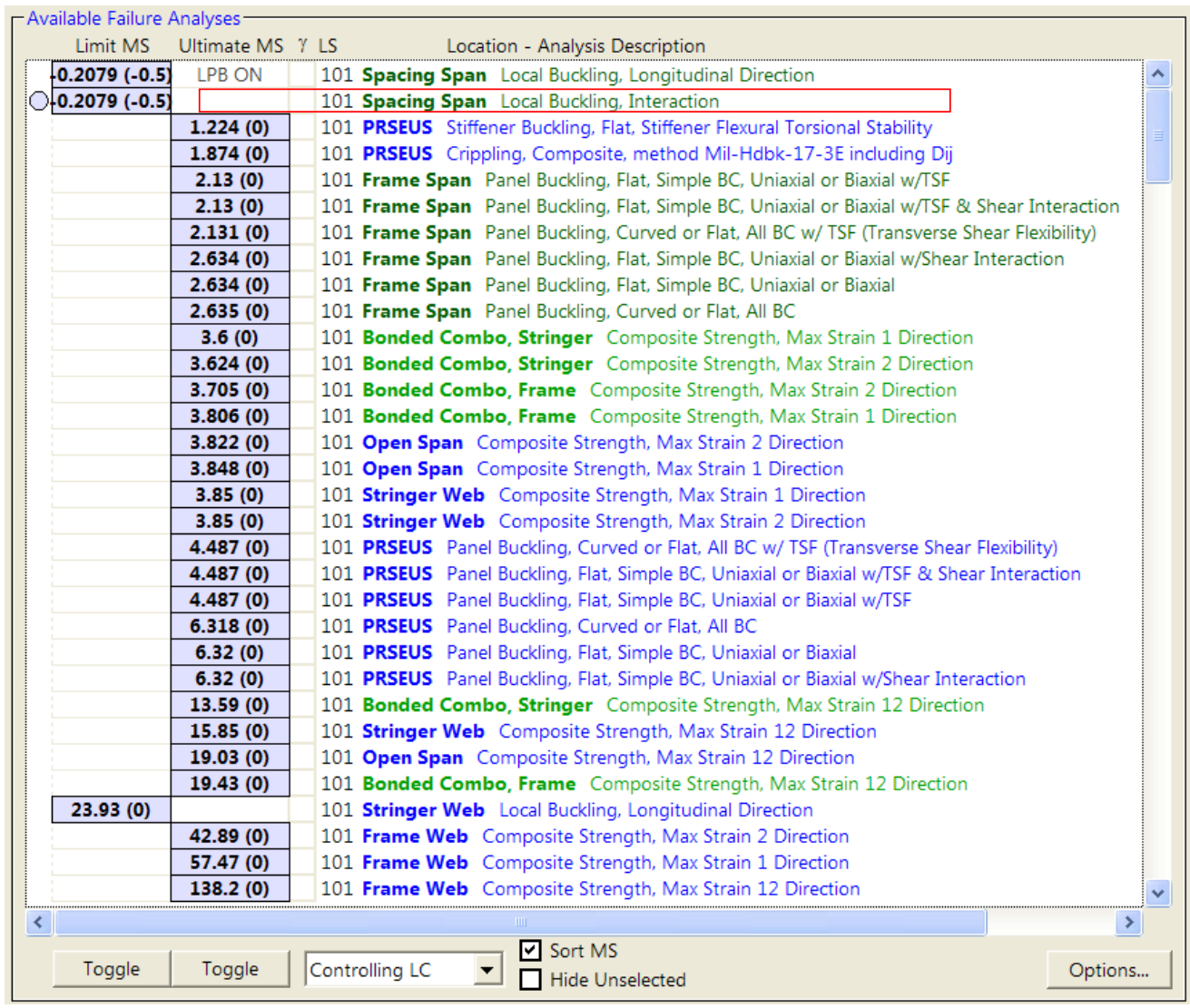

Figure 35.-Simulated PRSEUS panel margins of safety. 




Figure 36.-Abaqus FE model prediction for the postbuckling load versus strain response for the simulated PRSEUS panel.

\subsubsection{FEA Verification of Postbuckling Strength}

To verify any postbuckling result, linear static and eigenvalue FEA is no longer sufficient. The user must rely on a geometric nonlinear finite element analysis to verify any post-buckled results. The same PRSEUS discrete model FE model from the previous section was analyzed using geometric nonlinear analysis in ABAQUS.

The postbuckling load versus strain response is shown in Figure 36. In nonlinear postbuckling analysis, it is difficult to ascertain what constitutes a "buckling" event. In the results shown here, two events are used to determine when buckling occurs. First, negative eigenvalue buckling refers to the solver reporting negative eigenvalues while decomposing the stiffness matrix for inversion. The first negative eigenvalues shown in the following figure indicate the onset of local buckling. A secondary event that indicates the presence of local buckling is a change in the panel-stiffness matrix. These are shown below and indicate secondary buckling events such as a mode change, or the final panel collapse.

In the current results, three principle responses were detected. First, local buckling onset occurred at approximately $2570 \mathrm{lb} / \mathrm{in}$. (108 kips). This is slightly higher than the load, 85 kips, predicted from linear eigenvalue analysis. A secondary event occurs when the local buckling modes change from two to three half-waves at approximately 159 kips. Finally the panel continues loading to a final collapse load of 229 kips. This compares favorably to the postbuckled HyperSizer Torsional value of 222 kips.

The ultimate failure mode from the nonlinear analysis can be determined by examining the deflected mode shapes. First, the initial local buckling mode shape at a load of 108 kips. The local buckled shapes can be seen in the second and fourth bays and are beginning to develop in the third, Figure 37. These mode shapes match the linear eigenvalue mode shapes (not shown). The color contours represent the relative magnitude of out-of-plane deflection.

The second event is the mode shift that occurs at approximately 159 kips. Notice that there are now three half-waves in the 2nd and 4th span and two half waves in the center span, Figure 38. Also notice that we are starting to see a slight perturbation of the stiffener.

The final result snapshots for this analysis are at a point just before final collapse. This result is at 229 kips. Notice that there is substantial deformation of the straight stiffener path as the stiffeners are starting to tip substantially, Figure 39. 
Also of note is the deformed shape of the panel shown from the side, Figure 40. As the stiffeners tip the load that they are carrying is beginning to offload from the very stiff rod into the facesheet. As this happens the effective bending stiffness of the panel is rapidly diminishing and the panel is beginning to take on a flexural (i.e., panel) buckling mode shape.

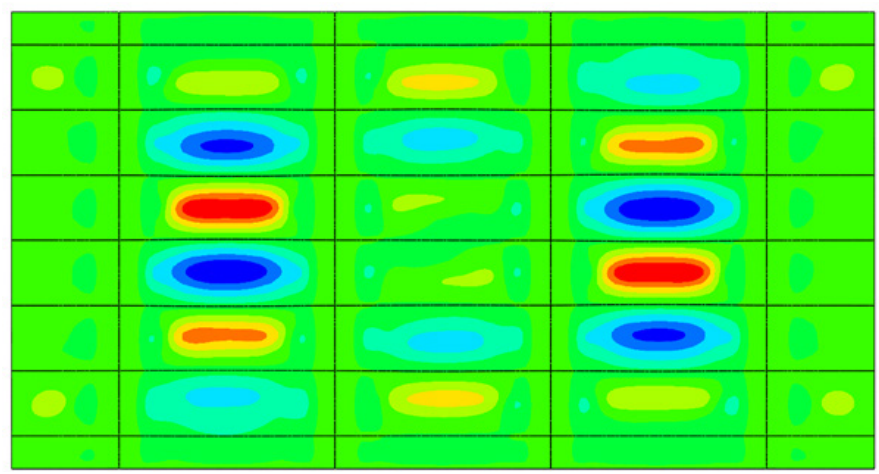

Figure 37.-First mode shape present in the Abaqus FEA local postbuckling simulation of the PRSEUS panel.

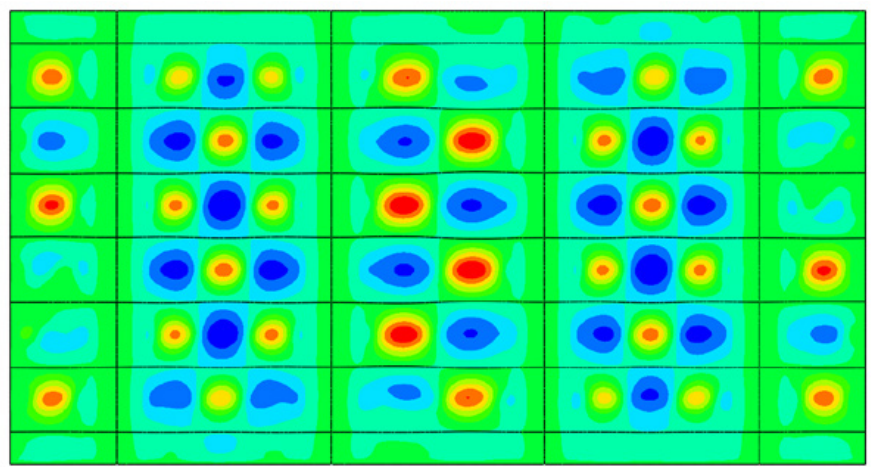

Figure 38.--Second mode shape present in the Abaqus FEA local postbuckling simulation of the PRSEUS panel.

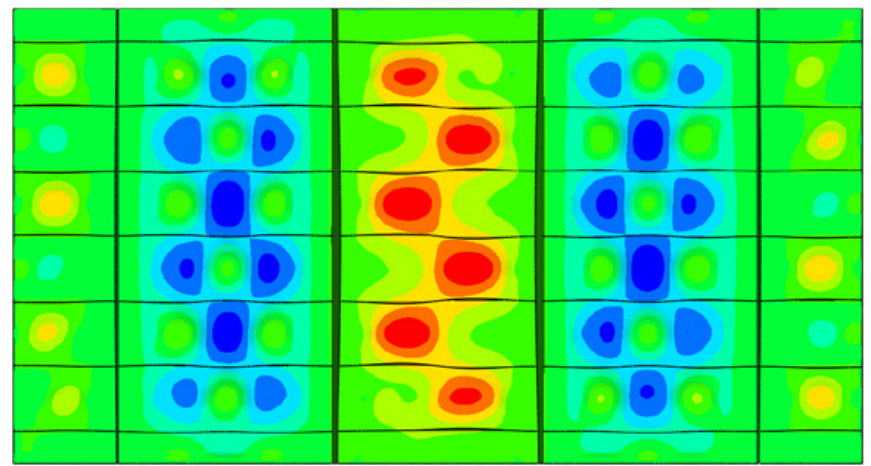

Figure 39.-Final mode shape in the Abaqus FEA local postbuckling simulation of the PRSEUS panel. 




Figure 40.-Final mode shape in the Abaqus FEA local postbuckling simulation of the PRSEUS panel, viewed from the side.

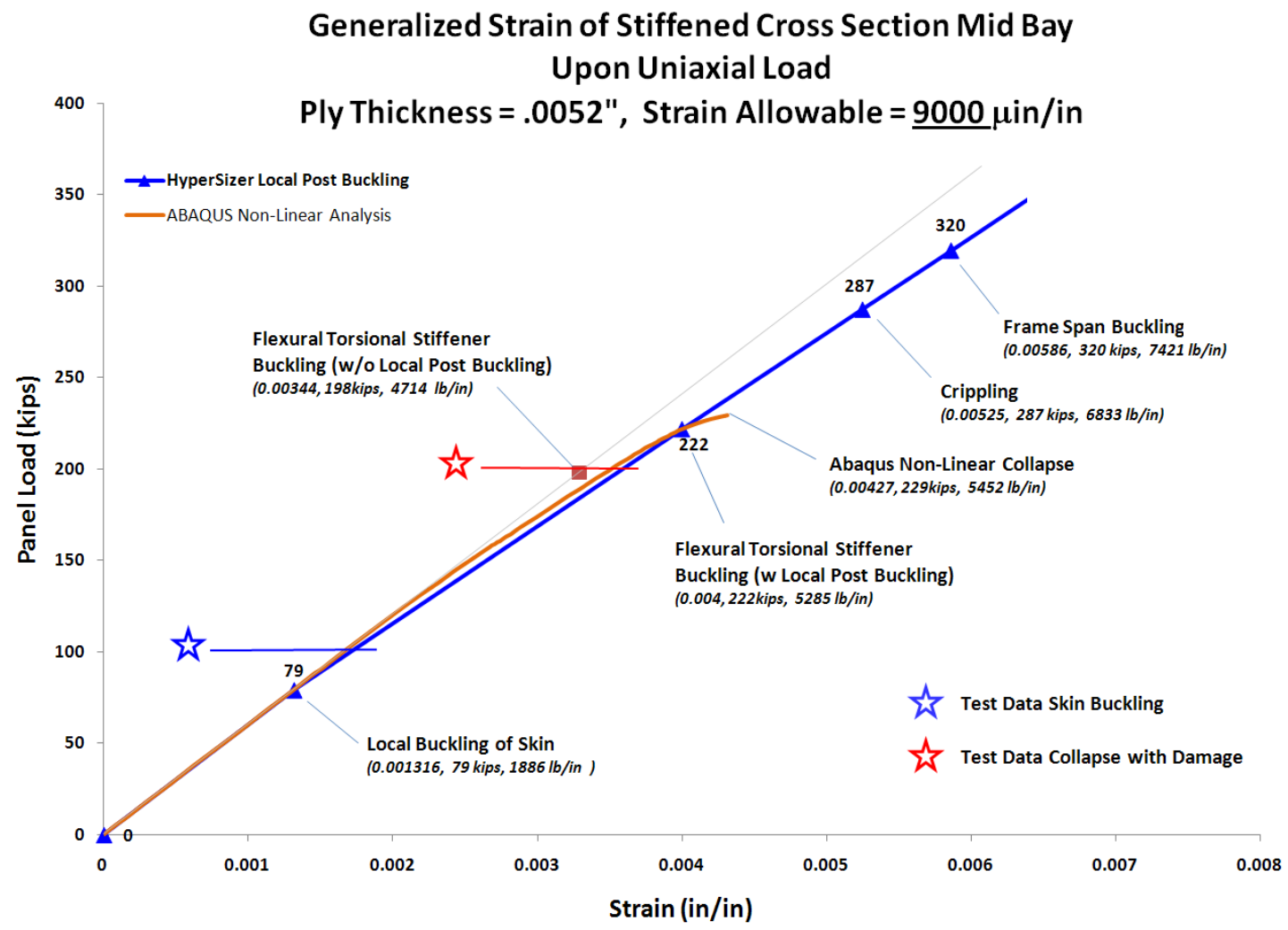

Figure 41.--Plot of linear elastic load-strain versus nonlinear postbuckling load-strain.

So, in summary, the nonlinear FEA shows a torsional buckling mode of the stiffeners which leads very quickly to panel collapse by overall panel buckling. The load level of collapse is 229 kips which compares favorably to HyperSizer’s predicted failure mode of torsional buckling at 222 kips.

\subsubsection{Validation to Test Data}

The single stack PRSEUS panel was tested to failure at NASA Langley in 2009 where the panel was subjected to uniform compressive load. One of the purposes of the test was to assess the damage tolerant capability of PRSEUS, therefore the panel was impacted prior to testing. Local buckling of the skin was observed in the test at just over 100 kips and the panel ultimate failure occurred at 199 kips. In Figure 41, the ABAQUS nonlinear response is shown as the orange line, compared with HyperSizer's nonlinear response shown as a blue line. In addition to the predicted failure load of 222 kips, the plot also shows HyperSizer's prediction for local buckling of the skin, stiffener crippling and frame span buckling. 

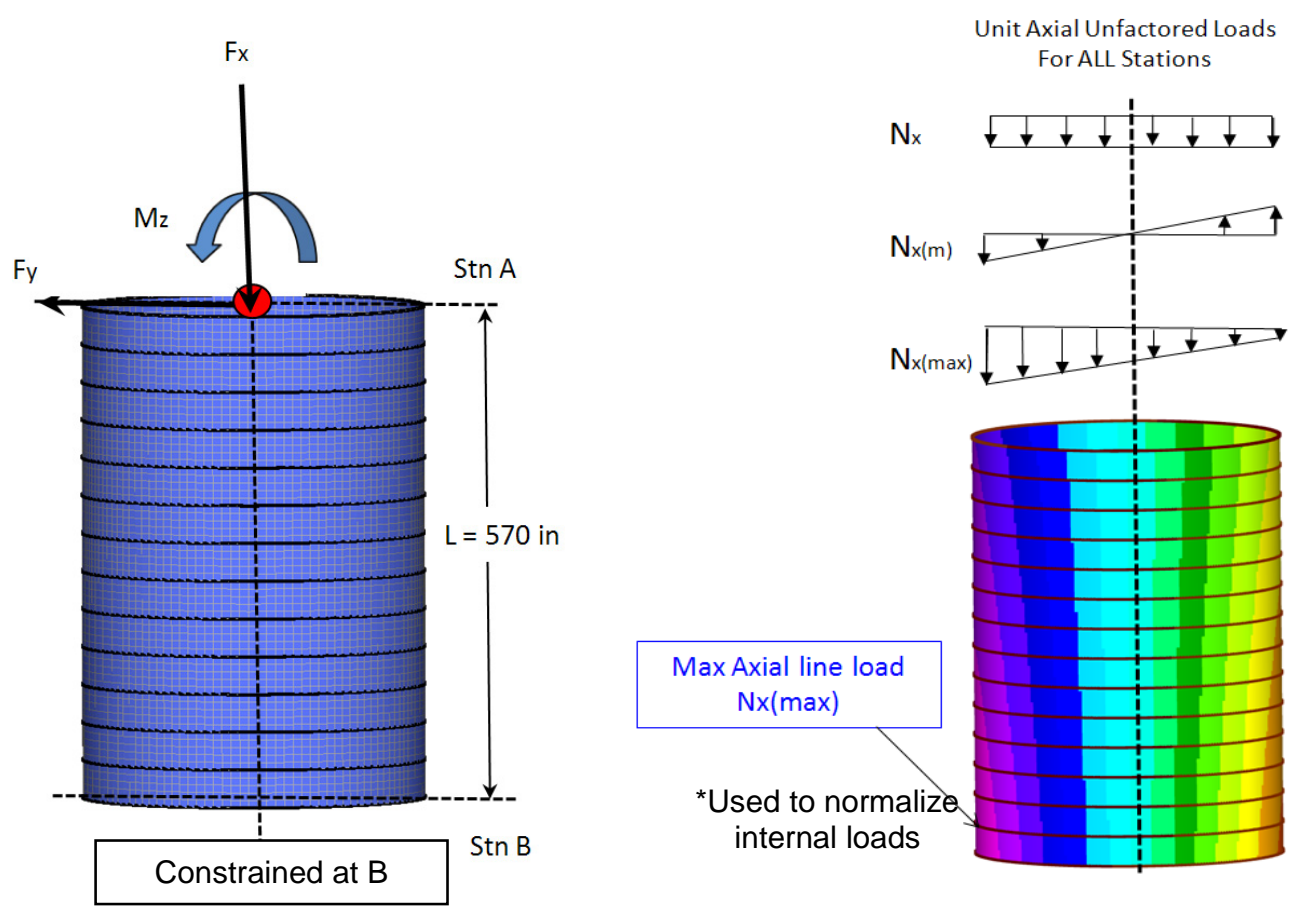

Figure 42.-Ares $\mathrm{V}$ Interstage internal axial (Nx) loads due to flight conditions.

\subsubsection{Sizing Results}

To illustrate the sizing capability of the new HyperSizer PRSEUS capability, a PRSEUS Panel for the NASA Ares V Interstage has been sized. The primary load supported by the NASA Ares V Interstage is axial compression from a combination of vertical acceleration and the bending moment. However, two other loadings must be considered: (1) hoop tension caused by the internal pressurization (2) compressive hoop load caused by crushing pressure. This combination of biaxial loads including hoop compression makes the PRSEUS panel concept, with its transverse frames especially desirable. To determine static loads, the external axial, moment, and shear loads are applied to the top of the cylindrical Interstage. The reaction loads are derived at the bottom of the Interstage. Figure 42 shows how the flight loads are applied to derive the internal loads. See Reference 22 for more details on loading and sizing results.

Though the loading is statically determinate, FEA is used to resolve the external flight loads into internal element loads, that includes the effects of ringframe hoop load sharing. The maximum line load at the base of the Interstage results from the combination of axial and moment load. During this study NASA required the entire barrel is to be the same design—so the entire barrel from bottom to top is sized to the maximum line load experienced at station B.

Optimum PRSEUS results derived during the Ares V interstage study (Ref. 22) are shown in Figure 43. PRSEUS has one advantage over other panels concepts in that frame is integral to the stiffened panel, where other panel concepts require a separate ringframe for global stability. The optimum PRSEUS design has a frame spacing of $52 \mathrm{in}$. and a stringer spacing of $7.5 \mathrm{in}$. The unit weight is $2.02 \mathrm{lb} / \mathrm{ft}^{2}$.

Margins of safety for each failure analysis in the HyperSizer Failure tab are shown in Figure 44. With the given panel sizing, the panel is controlled by global panel buckling. Because this concept adds stitching to the flange to skin bondline, it is allowed to postbuckle (LPB). Initial skin buckling is allowed at 75 percent limit load. 


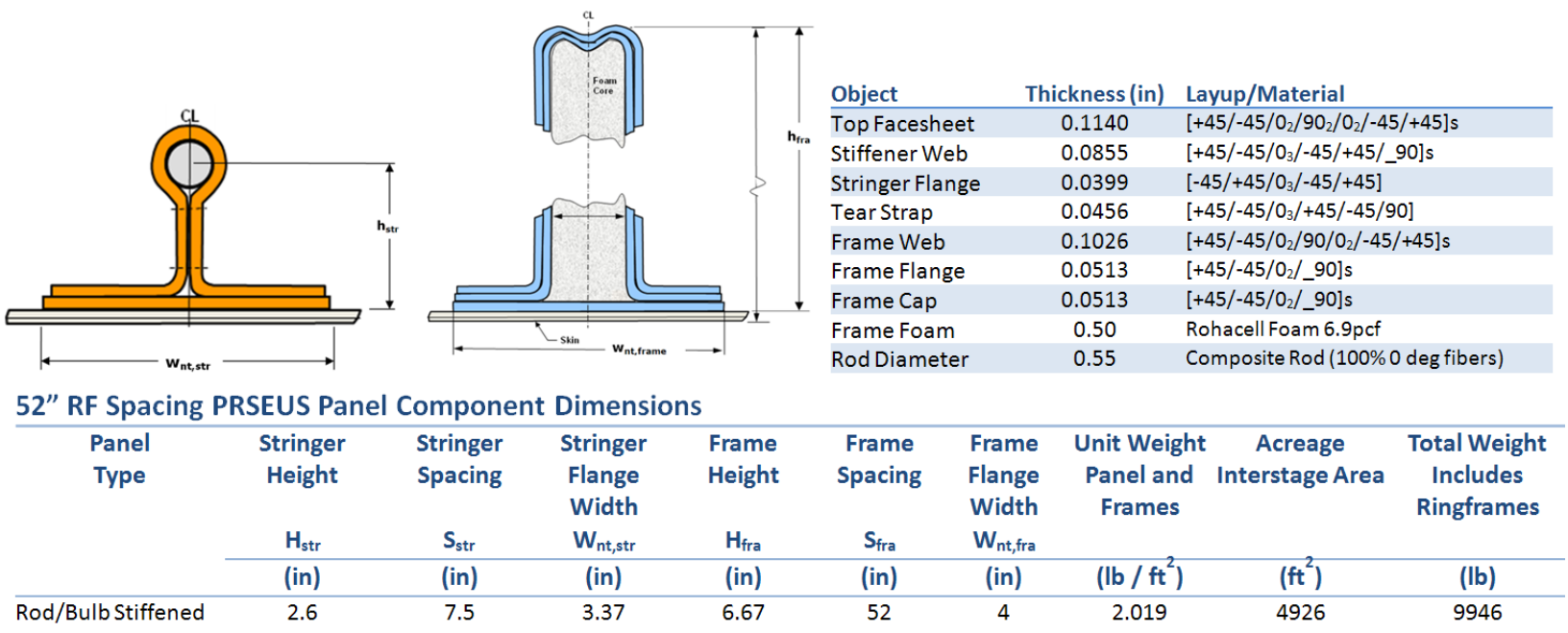

Figure 43.-HyperSizer sizing results for the PRSEUS Ares V interstage acreage panel.

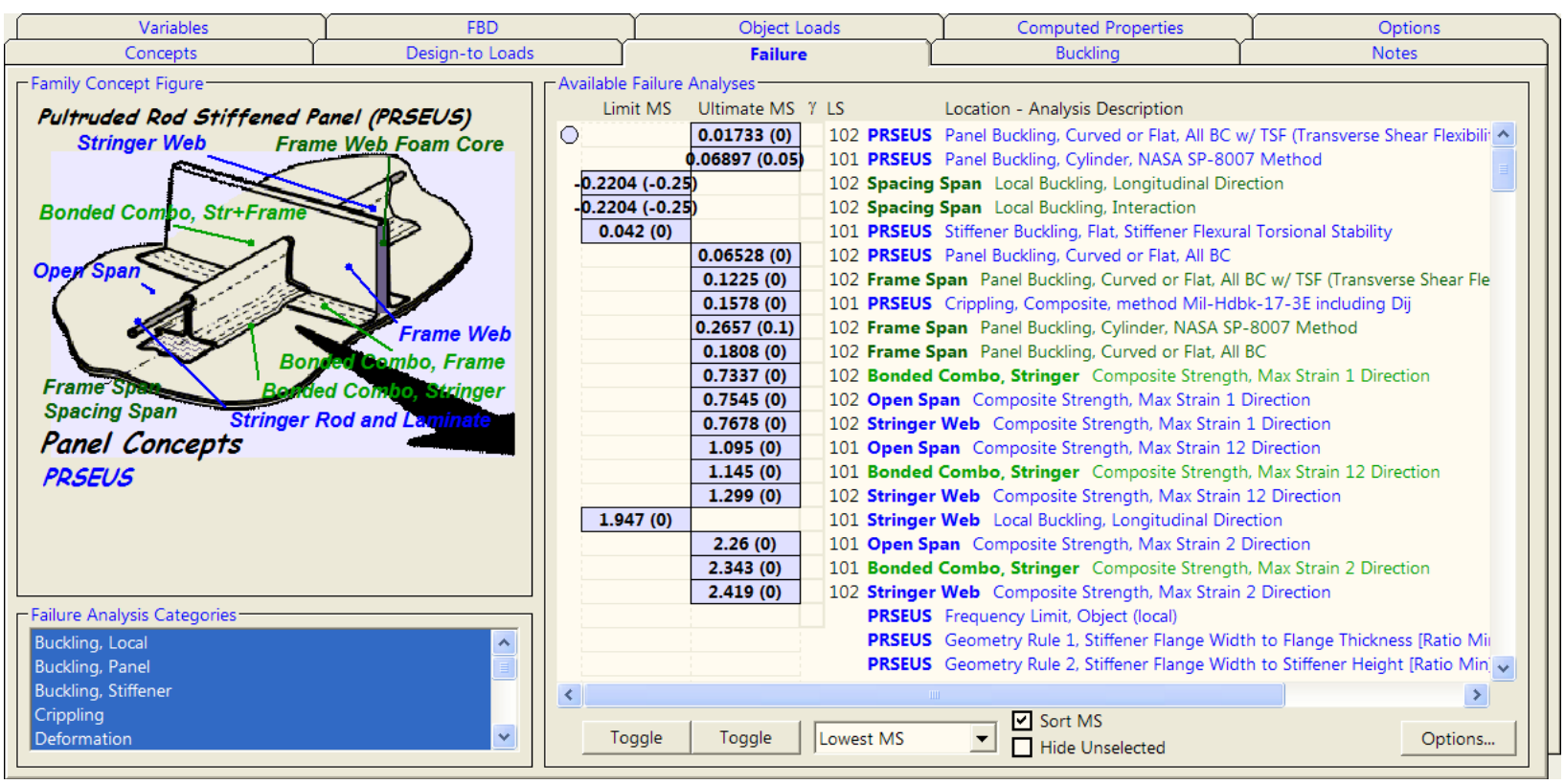

Figure 44.- HyperSizer margin of safety results for the PRSEUS Ares V interstage acreage panel.

\subsection{Conclusions}

New design and sizing capabilities have been developed and incorporated into the HyperSizer Structural Sizing Software for two novel composite panel concepts. Reinforced core sandwich (RCS) panels combine aspects of foam core sandwich panels and stiffened panels in a concept that includes integral composite webs for optimum through-thickness shear capabilities and excellent damage tolerance. Boeing's Pultruded Rod Stitched Efficient Unitized Structure (PRSEUS) panels rely on precured unidirectional composite rods for high axial stiffness, integral foam core frames of transverse support, and stitching for superior damage tolerance. Both concepts are resin-infiltrated and oven-cured, which can provide manufacturing efficiencies. This paper outlines the new methods that have been developed and incorporated into HyperSizer to determine the local forces, stresses, and strains and to predict the failure loads associated with the many failure modes that have been observed for these new composite panel concepts. Verification and validation results been shown for the new methods, and 
example sizing results have illustrated the utility of these new HyperSizer capabilities. Both RCS and PRSEUS panels, as available structural concepts within HyperSizer, can now be applied widely in lightweight composite structural design.

\section{References}

1. HyperSizer Structural Sizing Software, Collier Research Corp., Hampton, VA, http://www.hypersizer.com, 2010.

2. Stoll, F., Day, S., Campbell, S., Banerjee, R., Sheppard, M., and Lang, E., “Advancements in Engineered Composite Sandwich Core Materials,” SAMPE 2006, May, Long Beach, CA, 2006.

3. WebCore Technologies, Inc., Miamisburg, OH, http://www.webcoreonline.com, 2010.

4. Velicki, A and Thrash, P., "Advanced Structural Concept Development Using Stitched Composites," 49th AIAA/ASME/ ASCE/AHS/ASC Structures, Structural Dynamics, and Materials Conference, Schaumburg, IL, April 2008, AIAA 2008-2329.

5. Bednarcyk, B.A., Arnold, S.M., Collier, C.S., and Yarrington, P.W. "Preliminary Structural Sizing and Alternative Material Trade Study for CEV Crew Module," 48th AIAA/ASME/ASCE/AHS/ASC Structures, Structural Dynamics, and Materials Conference, Honolulu, HI, April 2007, AIAA 20072175.

6. Bednarcyk, B.A., Arnold, S.M, and Hopkins, D.A., "Design of Fiber Reinforced Foam Sandwich Panels for Large Ares V Structural Applications," 51st AIAA/ASME/ASCE/AHS/ASC Structures, Structural Dynamics, and Materials Conference, Orlando, FL, April, 2010, AIAA 2010-2781.

7. Zalewski, B.F. and Bednarcyk, B.A., “ACT Payload Shroud Structural Concept Analysis and Optimization,” NASA/TM-2010-216942, 2010.

8. Berg, J.S. and Higgins, J., "VARTM Infusion: Processing Large Carbon/Epoxy Space Structures Out of the Autoclave,” SAMPE Journal, Vol. 44, No. 6, pp. 41-44, 2008.

9. Yovanof, N.P, Velicki, A., and Li, V. "Advanced Structural Stability Analysis of a Noncircular, BWB-Shaped Vehicle” 50th AIAA/ASME/ASCE/AHS/ASC Structures, Structural Dynamics, and Materials Conference, Palm Springs, CA, May, 2009, AIAA 2009-2452.

10. Ley, R. P., Lin, W., Mbanefo, U., "Facesheet Wrinkling in Sandwich Structures”, NASA/CR—1999208994, 1999.

11. Whitney, J.M., Structural Analysis of Laminated Anisotropic Plates, Technomic, Lancaster, PA, 1987.

12. Timoshenko, S. P. and Gere, J. M., Theory of Elastic Stability, McGraw-Hill, 1961.

13. Hetenyi, M., Beams on Elastic Foundation, University of Michigan Press, 1946.

14. Collier, C., "Stiffness, Thermal Expansion, and Thermal Bending Formulation of Stiffened, FiberReinforced Composite Panels,” 34th AIAA/ASME/ASCE/AHS/ASC Structures, Structural Dynamics, and Materials Conference, La Jolla, April 1993, AIAA 93-1569.

15. Collier, C., "Thermoelastic Formulation of Stiffened, Unsymmetric Composite Panels for Finite Element Analysis of High Speed Aircraft,” 35th AIAA/ASME/ASCE/AHS/ASC Structures, Structural Dynamics, and Materials, Hilton Head, SC, April 1994, AIAA 94-1579.

16. Collier, C., Yarrington, P., and Van West, B., "Composite, Grid Stiffened Panel Design for Post Buckling Using HyperSizer” 43rd AIAA/ASME/ASCE/AHS/ASC Structures, Structural Dynamics, and Materials Conference, Denver, CO, 2002.

17. Collier, C., Yarrington, P., Gustafson, P., and Bednarcyk, B., "Local Post Buckling: An Efficient Analysis Approach for Industry Use,” 50th AIAA/ASME/ASCE/AHS/ASC Structures, Structural Dynamics, and Materials Conference. Palm Springs, CA, 2009.

18. Argyris, J., Flexural-Torsion Failure of Panels. Aircraft Engineering, 1954.

19. Seydel, E., "On the Buckling of rectangular isotropic and or orthogonal-isotropic plates by tangential stresses,” Ing Archiv., 1933.

20. Evonic Industries, Rohacell IG/IG-F Datasheet, http://www.rohacell.com/en/performanceplastics8344.html, Aug. 2009. 
21. Jegley, D. C., Alexander V., and Hanson, D. A., "Structural Efficiency Of Stitched Rod-Stiffened Composite Panels With Stiffener Crippling,” 49th AIAA/ASME/ASCE/AHS/ASC Structures, Structural Dynamics, and Materials Conference, Schaumburg, IL, April 2008.

22. Collier, C., Ainsworth, J., Yarrington, P., and Lucking, R., "Ares V Interstage Composite Panel Concept and Ringframe Spacing Trade Studies,” 51st AIAA/ASME/ASCE/AHS/ASC Structures, Structural Dynamics, and Materials Conference, Orlando, FL, April 2010. 



\begin{tabular}{|c|c|c|c|c|c|}
\hline \multicolumn{5}{|c|}{ REPORT DOCUMENTATION PAGE } & $\begin{array}{l}\text { Form Approved } \\
\text { OMB No. 0704-0188 }\end{array}$ \\
\hline \multicolumn{6}{|c|}{$\begin{array}{l}\text { The public reporting burden for this collection of information is estimated to average } 1 \text { hour per response, including the time for reviewing instructions, searching existing data sources, gathering and maintaining the } \\
\text { data needed, and completing and reviewing the collection of information. Send comments regarding this burden estimate or any other aspect of this collection of information, including suggestions for reducing this } \\
\text { burden, to Department of Defense, Washington Headquarters Services, Directorate for Information Operations and Reports (0704-0188, } 1215 \text { Jefferson Davis Highway, Suite } 1204, \text { Arlington, VA } 22202-4302 \text {. } \\
\text { Respondents should be aware that notwithstanding any other provision of law, no person shall be subject to any penalty for failing to comply with a collection of information if it does not display a currently valid OME } \\
\text { control number. } \\
\text { PLEASE DO NOT RETURN YOUR FORM TO THE ABOVE ADDRESS. }\end{array}$} \\
\hline \multicolumn{2}{|c|}{$\begin{array}{l}\text { 1. REPORT DATE (DD-MM-YYYY) } \\
01-12-2011\end{array}$} & \multicolumn{3}{|c|}{$\begin{array}{l}\text { 2. REPORT TYPE } \\
\text { Technical Memorandum }\end{array}$} & 3. DATES COVERED (From - To) \\
\hline \multirow{3}{*}{\multicolumn{5}{|c|}{$\begin{array}{l}\text { 4. TITLE AND SUBTITLE } \\
\text { Efficient Design and Analysis of Lightweight Reinforced Core Sandwich and PRSEUS } \\
\text { Structures }\end{array}$}} & 5a. CONTRACT NUMBER \\
\hline & & & & & 5b. GRANT NUMBER \\
\hline & & & & & 5c. PROGRAM ELEMENT NUMBER \\
\hline \multirow{3}{*}{\multicolumn{5}{|c|}{$\begin{array}{l}\text { 6. AUTHOR(S) } \\
\text { Bednarcyk, Brett, A.; Yarrington, Phillip, W.; Lucking, Ryan, C.; Collier, Craig, S.; } \\
\text { Ainsworth, James, J.; Toubia, Elias, A. }\end{array}$}} & 5d. PROJECT NUMBER \\
\hline & & & & & 5e. TASK NUMBER \\
\hline & & & & & $\begin{array}{l}\text { 5f. WORK UNIT NUMBER } \\
\text { WBS } 944244.04 .02 .03\end{array}$ \\
\hline \multicolumn{5}{|c|}{$\begin{array}{l}\text { 7. PERFORMING ORGANIZATION NAME(S) AND ADDRESS(ES) } \\
\text { National Aeronautics and Space Administration } \\
\text { John H. Glenn Research Center at Lewis Field } \\
\text { Cleveland, Ohio 44135-3191 }\end{array}$} & $\begin{array}{l}\text { 8. PERFORMING ORGANIZATION } \\
\text { REPORT NUMBER } \\
\text { E-17883-1 }\end{array}$ \\
\hline \multirow{2}{*}{\multicolumn{5}{|c|}{$\begin{array}{l}\text { 9. SPONSORING/MONITORING AGENCY NAME(S) AND ADDRESS(ES) } \\
\text { National Aeronautics and Space Administration } \\
\text { Washington, DC 20546-0001 }\end{array}$}} & $\begin{array}{l}\text { 10. SPONSORING/MONITOR'S } \\
\text { ACRONYM(S) } \\
\text { NASA }\end{array}$ \\
\hline & & & & & $\begin{array}{l}\text { 11. SPONSORING/MONITORING } \\
\text { REPORT NUMBER } \\
\text { NASA/TM-2011-217198 }\end{array}$ \\
\hline \multicolumn{6}{|c|}{$\begin{array}{l}\text { 12. DISTRIBUTION/AVAILABILITY STATEMENT } \\
\text { Unclassified-Unlimited } \\
\text { Subject Category: } 39 \\
\text { Available electronically at http://www.sti.nasa.gov } \\
\text { This publication is available from the NASA Center for AeroSpace Information, 443-757-5802 }\end{array}$} \\
\hline \multicolumn{6}{|c|}{$\begin{array}{l}\text { 13. SUPPLEMENTARY NOTES } \\
\text { An Erratum was added to this }\end{array}$} \\
\hline \multicolumn{6}{|c|}{$\begin{array}{l}\text { 14. ABSTRACT } \\
\text { Design, analysis, and sizing methods for two novel structural panel concepts have been developed and incorporated into the HyperSizer } \\
\text { Structural Sizing Software. Reinforced Core Sandwich (RCS) panels consist of a foam core with reinforcing composite webs connecting } \\
\text { composite facesheets. Boeing's Pultruded Rod Stitched Efficient Unitized Structure (PRSEUS) panels use a pultruded unidirectional } \\
\text { composite rod to provide axial stiffness along with integrated transverse frames and stitching. Both of these structural concepts are oven- } \\
\text { cured and have shown great promise applications in lightweight structures, but have suffered from the lack of efficient sizing capabilities } \\
\text { similar to those that exist for honeycomb sandwich, foam sandwich, hat stiffened, and other, more traditional concepts. Now, with accurate } \\
\text { design methods for RCS and PRSEUS panels available in HyperSizer, these concepts can be traded and used in designs as is done with the } \\
\text { more traditional structural concepts. The methods developed to enable sizing of RCS and PRSEUS are outlined, as are results showing the } \\
\text { validity and utility of the methods. Applications include several large NASA heavy lift launch vehicle structures. }\end{array}$} \\
\hline \multicolumn{6}{|c|}{$\begin{array}{l}\text { 15. SUBJECT TERMS } \\
\text { Sandwich structures; Buckling; Panels; Failure; Composite structures; Structural design; Ares V; Finite element method; HyperSizer }\end{array}$} \\
\hline \multicolumn{3}{|c|}{ 16. SECURITY CLASSIFICATION OF: } & $\begin{array}{l}\text { 17. LIMITATION OF } \\
\text { ABSTRACT }\end{array}$ & $\begin{array}{l}\text { 18. NUMBER } \\
\text { OF }\end{array}$ & $\begin{array}{l}\text { 19a. NAME OF RESPONSIBLE PERSON } \\
\text { STI Help Desk (email:help@sti.nasa.gov) }\end{array}$ \\
\hline $\begin{array}{l}\text { a. REPORT } \\
U\end{array}$ & $\begin{array}{l}\text { b. ABSTRACT } \\
\mathrm{U}\end{array}$ & $\begin{array}{l}\text { c. THIS } \\
\text { PAGE } \\
\text { U }\end{array}$ & UU & $\begin{array}{l}\text { PAGES } \\
48\end{array}$ & $\begin{array}{l}\text { 19b. TELEPHONE NUMBER (include area code) } \\
443-757-5802\end{array}$ \\
\hline
\end{tabular}



